\title{
Numerical simulations of impact behaviour of thin steel plates subjected to cylindrical, conical and hemispherical non-deformable projectiles
}

\author{
A. Arias ${ }^{\mathrm{a}, *}$, J.A. Rodríguez-Martínez ${ }^{\text {a }}$, A. Rusinek ${ }^{\text {b }}$ \\ a Department of Continuum Mechanics and Structural Analysis, University Carlos III of Madrid, \\ Avda. de la Universidad 30, 28911 Leganés, Madrid, Spain \\ ${ }^{\mathrm{b}}$ Laboratory of Physics and Mechanics of Materials, UMR CNRS 75 54, University Paul Verlaine of Metz, \\ Ile du Saulcy, 57045 Metz cedex, France
}

\begin{abstract}
In this paper, a numerical study of normal perforation of thin steel plates impacted by different projectile shapes is reported. The numerical simulations of this problem have been performed using a finite element code, ABAQUS Explicit with a fixed and an adaptive mesh for the plate. To define the thermoviscoplastic behaviour of the material constituting the plate, the Johnson Cook model has been used. This homogeneous behaviour has been coupled with the Johnson Cook fracture criterion to predict completely the perforation process. Three kinds of projectile shape (blunt, conical and hemi spherical) have been simulated with a large range of impact velocities from 190 to $600 \mathrm{~m} / \mathrm{s}$. The analysis considers the influ ence of adiabatic shear bands, plastic work and the gradient of temperature generated in the plate. The numerical results predict correctly the behaviour projectile plate in agreement with experimental data published by other authors.
\end{abstract}

Keywords: Numerical simulation; Perforation; Ballistic limits; Adaptive mesh; Ductile fracture

\section{Introduction}

Impact on plates is a complex and complete problem including dynamic behaviour, fracture, damage, contact and friction. We observe an internal energy which is an irreversible thermodynamic process due to transfer of kinetic energy, dynamic plastic flow, elastic and plastic wave propagation and large plastic deformation at high strain rates inducing thermal softening responsible of instabilities. It has been observed during this kind of projectile-plate impacts (metal metal) [ll 3 3] that the nose shape of the projectile used changes the energy absorbed, the failure mode and the ballistic limit [1,2]. It is reported in [1,2] that a blunt projectile

\footnotetext{
${ }^{*}$ Corresponding author. Tel.: +34 91624 9161; fax: +34 916249430.

E mail address: aariash@ing.uc3m.es (A. Arias).
} 




at low impact velocity is better to perforate completely the plate due to the failure mode. In this example, Fig. $1 \mathrm{a}$ and $\mathrm{b}$, the failure mode is due to adiabatic shear band propagation inducing a plug ejection and reducing the ballistic limit. In this case, the plug diameter $\phi_{\mathrm{pl}}$ is close to the projectile diameter $\phi_{\mathrm{p}}$, and the distance between projectile-plate is $\delta_{\mathrm{w}} \rightarrow 0$ (Fig. 1b) (stage II), inducing locally very high shear strain rate $\dot{\gamma}$ up to $10^{4} \mathrm{~s}^{1}$, as observed frequently during high speed cutting

$$
\dot{\gamma}=\frac{V_{0}}{\delta_{\mathrm{w}}}
$$

This process is strongly coupled to hardening $\varepsilon^{\mathrm{p}}$, strain rate $\dot{\varepsilon}^{\mathrm{p}}$ and temperature $T\left[\begin{array}{ll}1 & 3\end{array}\right]$. Due to the local temperature increase $\Delta T\left(\sigma, \varepsilon^{\mathrm{p}}, \dot{\varepsilon}^{\mathrm{p}}\right)$ an adiabatic shear band (ASB) is generated, which induces a thermal softening caused by large plastic deformation localisation $\varepsilon^{\mathrm{p}}[1,2,46]$. On the contrary, at high velocity the projectiles with hemispherical and conical shapes provide higher residual velocities: the complete perforation of the plate is caused by ductile hole enlargement generating in some case a petalling failure mode as for example observed also for small plate thickness (Fig. 1c), [1,2]. The bending effect and compressive state are predominant in this failure mode without shear effect. Thus, as discussed previously to define precisely this kind of behaviour it is necessary to use a constitutive relation which involves strain $\varepsilon^{\mathrm{p}}$, strain rate $\dot{\varepsilon}^{\mathrm{p}}$ and temperature $T$ effects coupled with local temperature increase $\Delta T\left(\sigma, \varepsilon^{\mathrm{p}}, \dot{\varepsilon}^{\mathrm{p}}\right)$ responsible of instability [1]. It is also necessary to use a failure criterion allowing reproducing these kinds of experimental observations (Fig. 1). Numerically, several previous studies of structural impact on steel plates have been performed using FE LS-DYNA code [4,6,7]. 

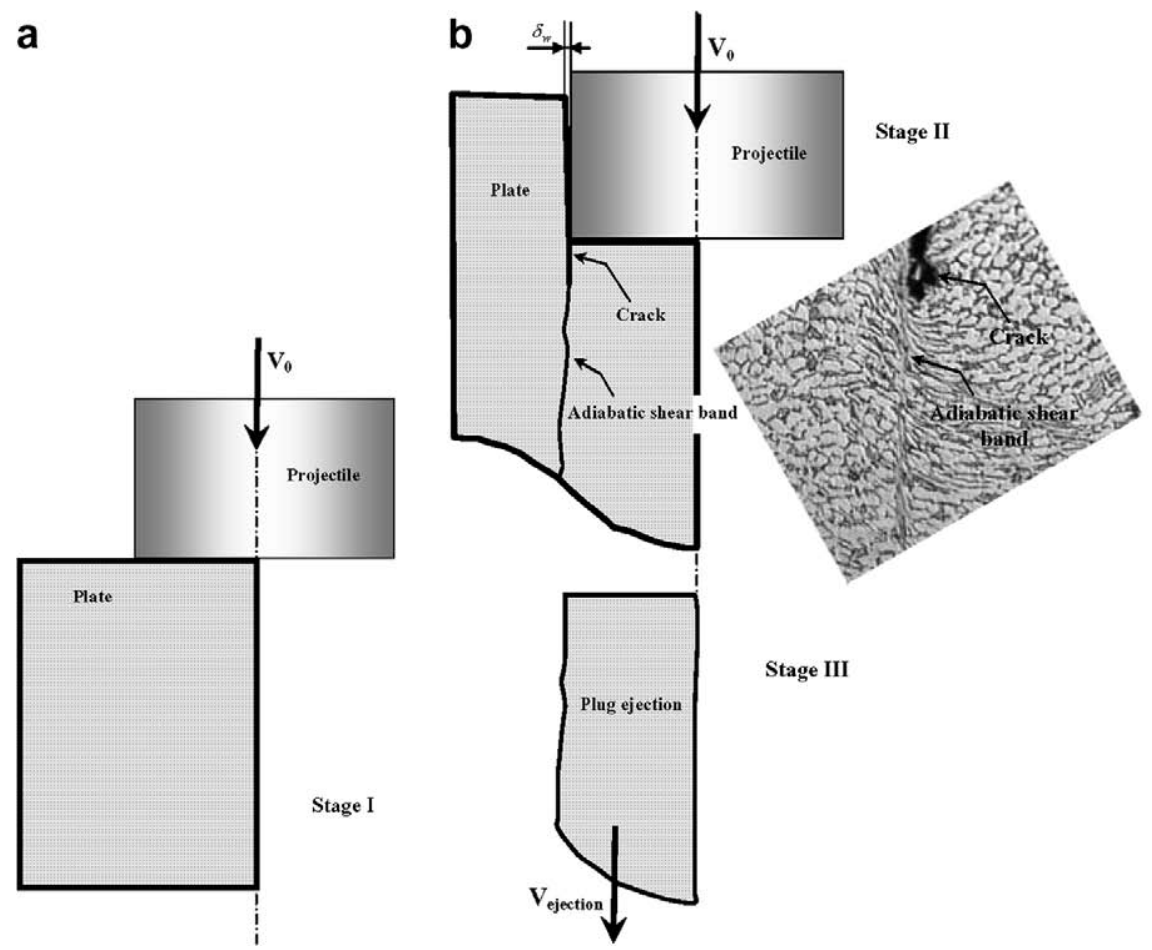

C

Fig. 1. Scheme of failure mode by blunt projectile. (a) Stage I impact; (b) stage II perforation process and initiation of adiabatic shear band [12]; stage III plug ejection and complete failure, (c) Petalling failure mode for thin plate and hemispherical projectile (impact velocity, $V_{\mathrm{o}}=57 \mathrm{~m} / \mathrm{s}$, projectile diameter $=22 \mathrm{~mm}$, plate diameter $\left.=50 \mathrm{~mm}\right)[13]$.

In these previous studies numerical problems occur when fixed meshes are used, specially using conical projectile [7]. Therefore, it is recommended to use an adaptive mesh for this configuration. The same observation was reported by Gupta et al. [2] studying numerically the problem of aluminium plate impact with ABAQUS FE code. In conclusion, the problem of plate impact perforation is not so easy to solve numerically due to element distortion caused by severe local loading. In this work, finite element simulations of steel plates impacted by cylindrical, conical and hemispherical non-deformable projectiles are performed using an explicit finite element code ABAQUS-Explicit [8], currently used for dynamic loading problems [2,9 11]. The numerical configuration used in terms of dimensions and boundary conditions is based on experimental set-up proposed by Borvik et al. [1]. Numerical results obtained allow to predict properly the complete process of perforation as it will be discussed in this paper. The analysis considers the influence of adiabatic shear band, gradient of temperature, and plastic work $W_{\mathrm{p}}$ generated in the plate during perforation process.

\section{Definition of the thermoviscoplastic behaviour}

The material plate, Weldox $460 \mathrm{E}$, is a thermo-mechanically rolled ferritic structural steel offering high strength combined with high ductility $\varepsilon_{\max }^{\mathrm{p}} \approx 1[1,4,14]$. The yield stress is about $\sigma_{\mathrm{y}} \approx 500 \mathrm{MPa}$ with a failure stress $\sigma_{\text {failure }} \geqslant 1 \mathrm{GPa}$. This material has been chosen since it is often studied and several experimental results have been published in tension and perforation $[1,4,15,16]$, which allow to validate numerical results. To define analytically this kind of thermoviscoplastic behaviour several approaches may be used as physical or phenomenological formulation. Moreover, in terms of phenomenological approach several constitutive relations exist [10,17 19]. In our case, the Johnson Cook model (JC), has been used to describe the behaviour observed at high impact velocity because it takes into account high strain rates sensitivity, large deformation and thermal softening. Moreover, this model is pre-implemented in ABAQUS-Explicit. The explicit formulation of the JC model is defined by: 
Table 1

Constants used to define the thermoviscoplastic behaviour of Weldox $460 \mathrm{E}$ steel at high strain rates in adiabatic conditions [4]

\begin{tabular}{llllllll}
\hline Elasticity & & & & & \\
\hline
\end{tabular}

$$
\sigma\left(\varepsilon^{\mathrm{p}}, \dot{\varepsilon}^{\mathrm{p}}, T\right)=\left[C_{1}+C_{2}\left(\varepsilon^{\mathrm{p}}\right)^{n}\right]\left[1+C_{3} \ln \left(\frac{\dot{\varepsilon}^{\mathrm{p}}}{\dot{\varepsilon}_{0}}\right)\right]\left[1-T^{* m}\right],
$$

where $C_{1}$ is the yield stress, $C_{2}$ is a constant of material, $n$ is the hardening parameter, $C_{3}$ is the strain rate sensitivity and $m$ is the temperature sensitivity parameter. $\dot{\varepsilon}_{0}$ is the lower limit of the constitutive relation and $T^{*} \quad\left(T-T_{0}\right) /\left(T_{\mathrm{m}}-T_{0}\right)$ is the homologous temperature, where $T$ is the current temperature, $T_{0}$ is the room temperature and $T_{\mathrm{m}}$ is the melting temperature. These constants are reported in Table 1 [4].

In addition, this constitutive relation coupled to the heat equation, Eq. (3), allows to obtain the temperature increase $\Delta T$, in adiabatic conditions

$$
\Delta T\left(\varepsilon^{\mathrm{p}}, \dot{\varepsilon}^{\mathrm{p}}, T_{0}\right)=\frac{\beta}{\rho C_{\mathrm{p}}} \int_{\varepsilon_{e}}^{\varepsilon^{\mathrm{p}}} \sigma\left(\varepsilon^{\mathrm{p}}, \dot{\varepsilon}^{\mathrm{p}}, T\right) \mathrm{d} \varepsilon^{\mathrm{p}},
$$

where $\beta$ is the Quinney Taylor coefficient which defines the plastic work part converted into heat. The value for steel is assumed constant and equal to $\beta \quad 0.9$ [20], $\rho$ is the density of the material and $C_{p}$ is the specific heat at constant pressure.

Fig. 2 shows the comparisons between experimental and analytical results reported in terms of strain rate sensitivity for different equivalent strain levels. Even if the strain rate sensitivity is not well defined, good results are obtained with the constants published by [4] in term of stress level. In fact, the non linear strain rate sensitivity of the material can not be defined using the JC model (dashed lines of Fig. 2) due to the analytical formulation, Eq. (2). The strain rate sensitivity of the material used in this study is reported on the following curve (Fig. 2), using different sets of constants published in the literature to define the thermoviscoplastic behaviour of Weldox $460 \mathrm{E}[4,9]$.

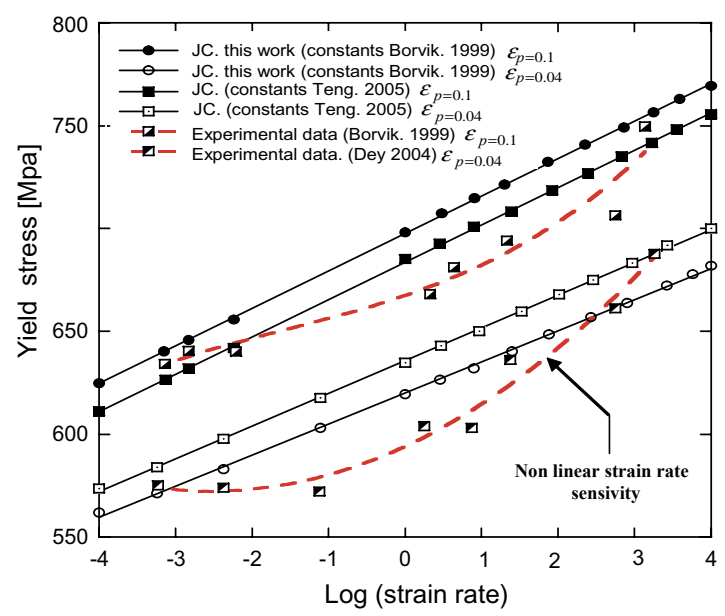

Fig. 2. Strain rate sensitivity for Weldox 460 E Steel. Experimental data and analytical results of JC model (Eq. (2)) using material constants from Borvik [4] and Teng [9]. 
To define completely the problem of plate impact perforation, the JC failure criterion has been used which considers the thermoviscoplastic effect.

\section{Fracture model based on the JC model}

The fracture model used in this study is extended from the criterion proposed by Hancock and Mackenzie [21]. The formulation has been proposed by Johnson and Cook [22] to include strain $\varepsilon^{\mathrm{p}}$, strain rate $\dot{\varepsilon}^{\mathrm{p}}$ and temperature $T$ dependencies. This model includes stress triaxiality $\sigma^{*}$, important parameter for this kind of application. Some results have also been reported in the literature concerning failure criterion dependency with stress triaxiality (see Fig. 3). Failure is assumed when a parameter $D$ exceeds unity. The $D$ parameter is summed over all increments of deformation. The evolution of $D$ is the following:

$$
D\left(\varepsilon^{\mathrm{p}}, \dot{\varepsilon}^{\mathrm{p}}, T, \sigma^{*}\right)=\sum\left(\frac{\Delta \varepsilon^{\mathrm{p}}}{\varepsilon_{\mathrm{f}}^{\mathrm{p}}\left(\dot{\varepsilon}^{\mathrm{p}}, T, \sigma^{*}\right)}\right)
$$

where $\Delta \varepsilon^{\mathrm{p}}$ is an increment of accumulated equivalent plastic strain that occurs during an integration cycle, and $\varepsilon_{\mathrm{f}}^{\mathrm{p}}$ is the critical failure strain level.

The plastic failure strain $\varepsilon_{\mathrm{f}}^{\mathrm{p}}$ is assumed to be dependent of a non-dimensional plastic strain rate $\dot{\varepsilon}^{\mathrm{p}} / \dot{\varepsilon}_{0}$, a dimensionless pressure deviatoric stress ratio $\left(\sigma^{*}=\sigma_{\mathrm{m}} / \sigma\right.$, where $\sigma_{\mathrm{m}}$ is the mean stress and $\sigma$ is the equivalent stress previously defined) and a non dimensional temperature $T^{*}$ as defined previously. The dependencies $\varepsilon_{\mathrm{f}}^{\mathrm{p}}=f\left(\sigma^{*}, \dot{\varepsilon}^{\mathrm{p}}, T\right)$ are assumed separable and take the following expression:

$$
\left\{\begin{array}{l}
\varepsilon_{\mathrm{f}}^{\mathrm{p}}=\left[D_{1}+D_{2} \exp \left(D_{3} \sigma^{*}\right)\right]\left[1+D_{4} \ln \left(\frac{\varepsilon^{\mathrm{p}}}{\varepsilon_{0}}\right)\right]\left[1+D_{5} T^{*}\right] \\
\sigma^{*}=\frac{1}{3 \sigma}\left(\sigma_{1}+\sigma_{2}+\sigma_{3}\right)
\end{array}\right.
$$

where $D_{i}$ are failure constants depending on materials used. The constants used for the material considered and published by Borvik et al. [4] are given in Table 2.

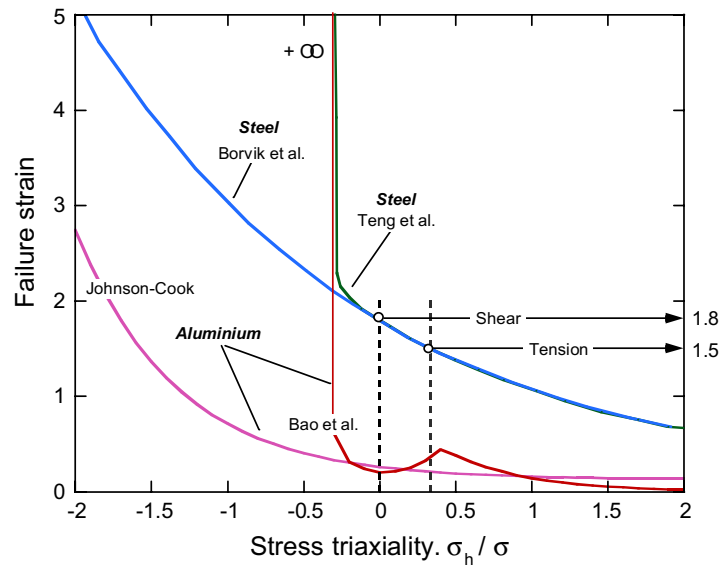

Fig. 3. Failure strain level depending on solicitation state [15] for different materials.

Table 2

Constants used to define fracture model [4]

\begin{tabular}{llccc}
\hline Fracture criterion constants & & & & \\
\hline$D_{1}$ & $D_{2}$ & $D_{3}$ & $D_{4}$ & $D_{5}$ \\
\hline 0.0705 & 1.732 & 0.54 & 0.0123 & 0 \\
\hline
\end{tabular}




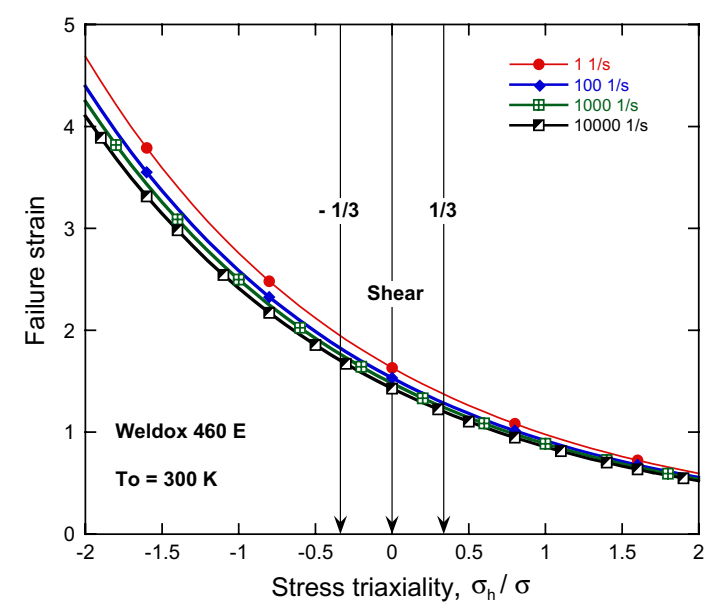

Fig. 4. Failure criterion used in this work for steel alloys (Eq. (5)).

In fact, the fracture model criterion is based on an equivalent plastic strain value $\varepsilon^{\mathrm{p}}$ to the element integration point. It is observed that the strain rate in our case induces only a small decrease of the failure strain level (Fig. 4). The value is close to $\varepsilon_{\mathrm{f}}^{\mathrm{p}} \rightarrow 1.5$ in shear and $\varepsilon_{\mathrm{f}}^{\mathrm{p}} \rightarrow 1.3$ in tension. The two stress states are responsible for the failure in this specific application reported in this paper.

This kind of fracture model based on a failure strain level is frequently used for dynamic application since at very high velocity, the failure strain level $\varepsilon_{\mathrm{f}}^{\mathrm{p}}$ is almost constant $[23,24]$.

The value generally observed is close to $1.2 \leqslant \varepsilon_{\text {failure }}^{\mathrm{p}} \leqslant 1.5$ in tension $[10]$ and $1.4 \leqslant \varepsilon_{\text {failure }}^{\mathrm{p}} \leqslant 1.6$ in shear (Figs. 3 and 4). This kind of fracture model is erosive in ABAQUS inducing an instantaneous element deletion [8] when an imposed plastic strain level is reached. Thus, using this kind of criterion the mesh in the damaged part must be very fine to not affect the numerical results in terms of energy.

\section{Numerical simulations using ABAQUS explicit}

\subsection{Experimental configuration}

The numerical simulations have been based on the experimental set-up proposed by Borvik et al. [1]. The goal consists to launch via a gas gun a projectile directly on a steel plate with a thickness $h \quad 12 \mathrm{~mm}$ clamped on the external diameter, $\phi \quad 500 \mathrm{~mm}[1,4]$. In our case only the normal impact $\theta \quad 90^{\circ}$ configuration has been studied. It is clear, as it has been reported in the literature that the plate-projectile incident angle $\theta$ affects the failure mode directly, the ballistic limit and the penetration force $[25,26]$. The projectiles are machined with high strength steel in comparison with the plate to reduce plastic deformation of the projectile. The projectiles have the same diameter $\phi_{\text {projectile }} 20 \mathrm{~mm}$ and a constant mass of $m \approx 197 \mathrm{~g}$ for each nose shape configuration (Fig. 5).

Thus, for a given velocity $V_{0}$ the kinetic energy is the same without effect of nose shape, $E_{K}^{\text {initial }}$ constant. During the experimental tests the initial impact and residual velocities are measured using a laser optical



Fig. 5. Nose shape projectile used during numerical simulations. 
device $[1,4]$. By using high speed camera the perforation event is recorded allowing to estimate the velocity of the projectile during perforation $[1,4]$. This technique allows to have an estimation of the failure mode. The experimental results obtained by this technique and published in the literature are a reference and frequently used to validate this kind of application.

The impact velocities during experiments vary from $180 \leqslant V o \leqslant 452 \mathrm{~m} / \mathrm{s}$ allowing to define the ballistic limit [1] for different nose shapes (Fig. 6).

\subsection{Mesh definition and boundary conditions used during numerical simulations}

The numerical simulations for each case have been performed using axisymmetric mesh (Figs. 6 and 7). The steel plate with a diameter $\phi \quad 500 \mathrm{~mm}$ and a thickness $h \quad 12 \mathrm{~mm}$ has been meshed with CAX4R elements corresponding to four nodes and reduced integration [8]. The optimal mesh has been obtained using a convergence method (stability of the results without mesh dependency). The smaller size element $l_{0}$ defines directly the integration time step $\Delta t \propto l_{0} / C_{0}$ via elastic wave speed $C_{0}=\sqrt{ } E / \rho$. If the element length is strongly reduced the integration time reaches $\Delta t \rightarrow 0$. The mesh is denser in the contact zone projectile-plate to satisfy the conditions proposed by Zukas [27] with an initial element size of $0.2 \times 0.2 \mathrm{~mm}^{2}$. This value is close to $0.25 \times 0.2 \mathrm{~mm}^{2}$, used by Borvik et al. [7]. Therefore, the number of elements in the thickness is equal to 60 and the total number of elements for the plate is equal to 13800 elements with 9000 elements for the denser part (Fig. 7).

The projectile has been meshed with the same elements, with 5000 for the blunt shape, 3430 for the conical shape and 5180 for the hemispherical shape (Figs. 7 and 8). The projectile behaviour has been defined as elastic using a large value for the yield stress $\sigma_{\mathrm{y}} \quad 1900 \mathrm{MPa}[4,7]$ allowing to reduce plastic deformation in the projectile. The contact between the projectile and the plate has been defined with a penalty contact algorithm and a hard contact model, both of them available in ABAQUS-EXPLICIT [8]. The "hard contact" option allows to adjust automatically the stiffness, generated by the "penalty contact algorithm", to minimize penetration without adversely affecting the time increment.

In relation to frictional effects, several values have been used in the literature to define the dynamic frictional coefficient $\mu[7,8,28]$. In this work typical values of 0 for blunt projectiles and 0.05 for conical and hemispherical projectiles have been used [7].

Two kinds of procedures have been used during numerical simulations. The first was to use a fixed mesh in terms of length elements while the second was to use an adaptive mesh allowing to regenerate the mesh of the plate during time calculations. The first option is well defined and robust for problems involving small or moderate deformation (without severe distortion). For large deformation with strong element distortion, as in our case, the algorithm does not work efficiently and problem of convergence appears. Thus, the second option using adaptive mesh is better and does not alter the topology (elements and connectivity) of the mesh. The adaptive meshing in ABAQUS-Explicit combines the features of pure Lagrangian analysis (in which the mesh follows the material, as is usually the case in ABAQUS) and Eulerian analysis (in which the mesh is fixed

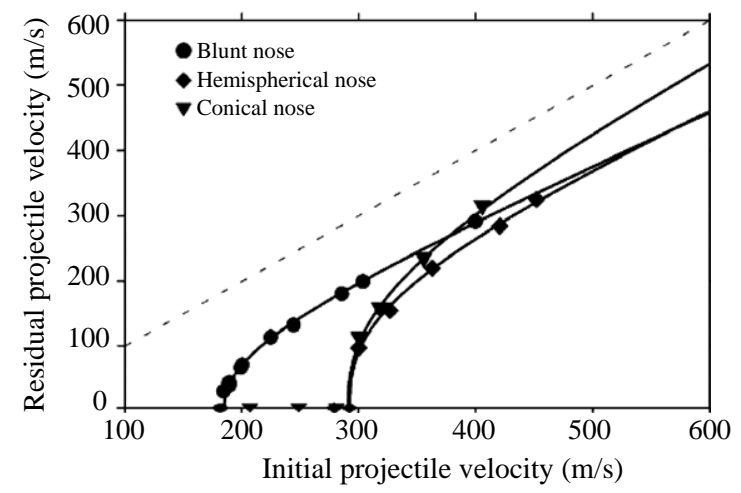

Fig. 6. Ballistic definition depending on the nose of the projectile [1]. 


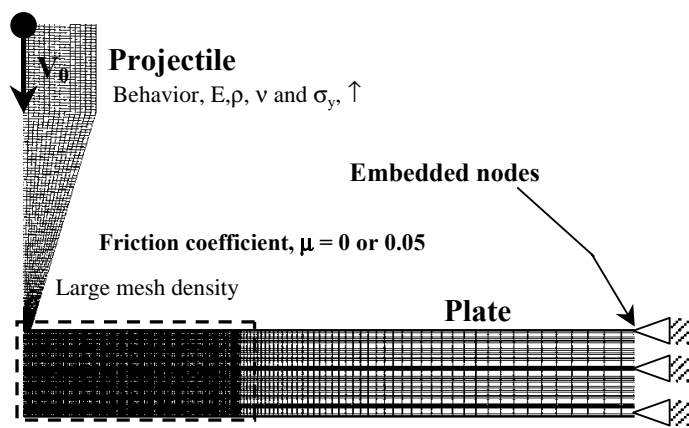

Fig. 7. Definition of the boundary conditions and mesh definition, conical configuration (C).
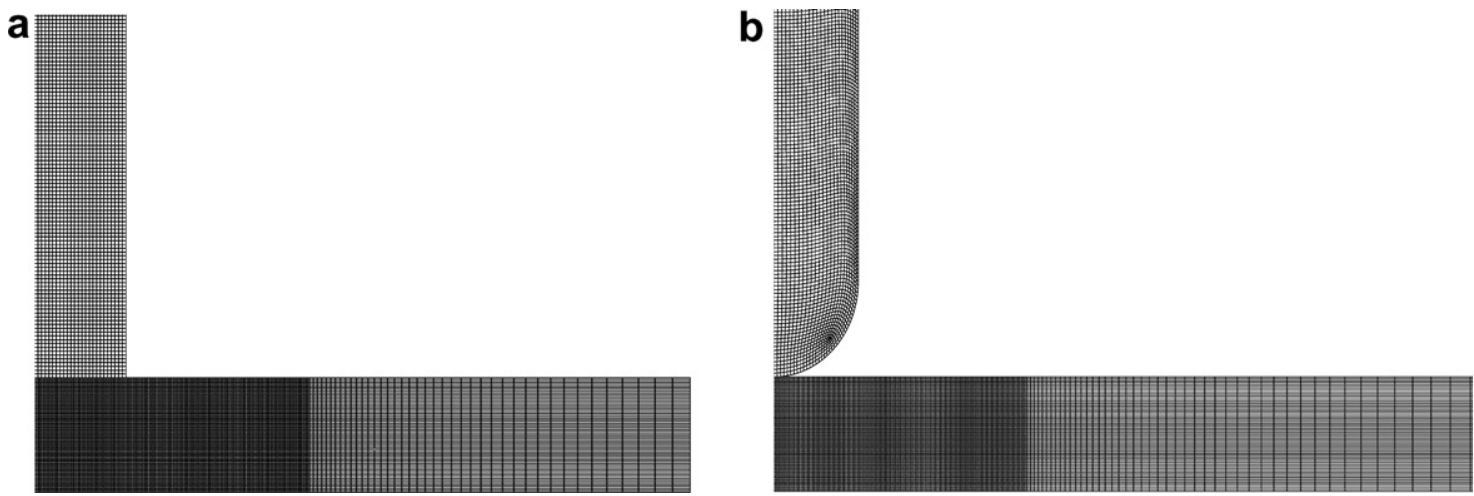

Fig. 8. Definition of the meshes used during numerical simulations: (a) blunt (B) and (b) hemispherical (H).

spatially and the material flows through the mesh) currently referred as Arbitrary Lagrangian Eulerian (ALE) analysis. In an adaptive mesh increment, a new, smoother mesh is created by sweeping iteratively over the adaptive mesh domain. During each mesh sweep, nodes in the domain are relocated based on the current positions of neighbouring nodes and elements to reduce element distortion. In a typical sweep a node is moved as a fraction of the characteristic length of any element surrounding the node. In our case the sweep mesh value has been assumed between 20 and 100, the lower value for blunt nose and high velocities while the upper value for conical projectiles and initial velocities close to the ballistic limit. This choice solves convergence problems during numerical simulation.

\section{Analysis of plate impact perforation}

The first considerations made during our numerical simulations were to observe the failure mode depending on the nose shape projectile used. It is shown on Figs. 10 12, that the failure mode for each case is in agreement with experimental observations. For blunt projectile, an adiabatic shear band initiation appears quickly, due to the geometric singularity of the projectile, after few microseconds. This adiabatic shear band generates a plug ejection as ultimate failure stage (Fig. 10e j).

Due to the fact that ASB is a very fast process, $600 \leqslant V_{\mathrm{C}} \leqslant 800 \mathrm{~m} / \mathrm{s}$ at high impact velocity, as reported by Molinari and Bonnet [29] (Fig. 9), the thickness of the plug for an applied velocity $V_{0}<600 \mathrm{~m} / \mathrm{s}$ is close to the initial thickness of the plate with the same diameter of the projectile (Fig. 10j).

However, at high initial impact velocity $V_{0} \quad 600 \mathrm{~m} / \mathrm{s}$, due to high compressive stage and trapping of plastic deformation close to the impact side (Fig. 10a), the thickness of the plug is reduced and smaller than the initial thickness. The trapping of plastic deformation close to the impact side is due to the critical impact velocity phenomenon (CIV) as reported by Klósak et al.[30]. In this precise case, the plastic wave celerity $C_{\mathrm{p}}$ reach 


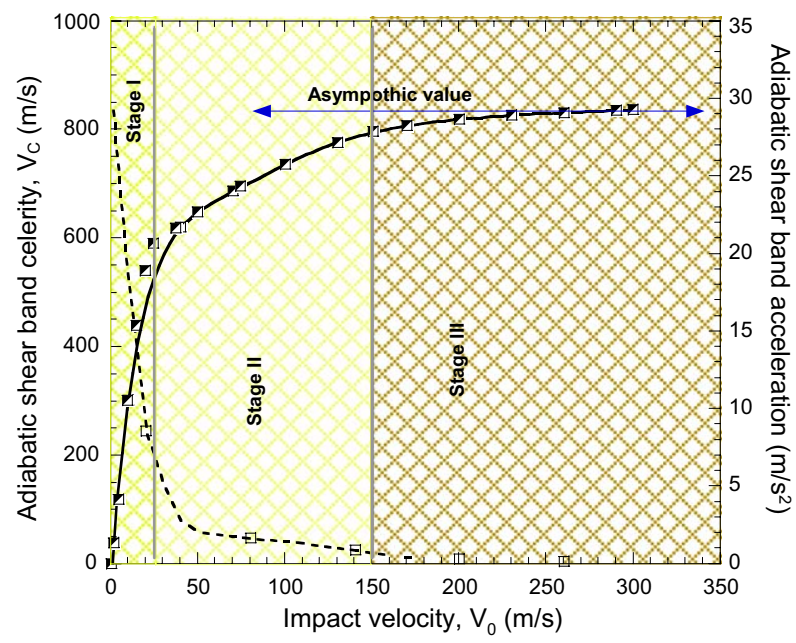

Fig. 9. Velocity of adiabatic shear band as a function of impact velocity [29].

zero, $C_{\mathrm{p}}=\sqrt{ } \partial \sigma / \partial \varepsilon_{\mathrm{p}}^{\mathrm{p}} / \rho$, due to thermal softening of the material [10]. Moreover, as shown previously (Fig. 9), the adiabatic shear band celerity $V_{C}$ has a plateau at very high applied velocity $\left(\lim _{V_{0}>150} \partial V_{C} / \partial V_{0} \rightarrow 0\right)$. Thus, if the initial impact velocity is close to the ASB velocity, it is possible to induce a compressive state inducing a length reduction of the plug. For $V_{0} \quad 600 \mathrm{~m} / \mathrm{s}$, the projectile is faster than the ASB propagation and the length of the plug, numerically obtained, is $l_{\text {plug }} 5 \mathrm{~mm}$. For lower impact velocities, $V_{0} \quad 190 \mathrm{~m} / \mathrm{s}$, the ASB is faster in comparison to the initial velocity, inducing a failure by ASB propagation and the length of the plug observed is equal to $l_{\text {plug }} 8.5 \mathrm{~mm}$. The reduction of the plug measured is due to the compressive state and due to numerical erosion of the material during the simulation. This effect is more accentuated at high impact velocities.

In the hemispherical case, the compressive and tension states induce a small plug ejection with a very thin thickness (Fig. 11b and c). The failure for hemispherical configuration is due to necking close to the contact zone projectile-plate. However, it is observed that for $V_{0} \quad 280 \mathrm{~m} / \mathrm{s}$ the necking appears on the top of the contact zone projectile-plate with hole enlargement due homogeneous plastic flow on the contact side (Fig. 11i and j). For high initial velocity due to trapping of plastic deformation on the impact side, the plastic flow is reduced inducing a circumferential necking (Fig. 11d). The same behaviour is observed experimentally using lubricated or dry condition for sheet steel [13] allowing to reduce or not the sliding between the projectile and the specimen [13]. On the contrary, it is observed that facilitating the plastic flow on the contact zone for low impact velocity or lubricated configuration, the necking appears on the top contact zone (Fig. 11i).

Concerning conical shape the force level observed is very low to perforate completely the plate at very high impact velocity $V_{0} \quad 600 \mathrm{~m} / \mathrm{s}$, inducing only a small decrease of the initial velocity and at the same time a low force level of perforation in comparison with $\mathrm{H}$ and B configuration, $F(t)=m \dot{V}(t)$ (Fig. 12). It is also observed for the ballistic velocity that the flexure effect is very important due to punctual contact in comparison with hemispherical and blunt shapes. For $\mathrm{H}$ and B projectiles the force is spread on a larger surface reducing the flexure effect.

Using numerical simulations, the residual velocity $V_{\mathrm{r}}$ has been estimated for all nose shapes (Figs. 13 15) and compared with experimental results published in [1]. The numerical results reported correspond to a fixed and an adaptive mesh. For each case, the numerical results are close to experimental results in terms of slope increase and ballistic limit estimation. For hemispherical and conical projectiles, at low impact velocity, the model provides slightly higher values of residual velocity than the experimental data. Different values of frictional coefficient for $\mathrm{H}$ and $\mathrm{C}$ configurations involve sensitive variations on numerical results (see Appendix). For blunt shape, the friction is less important due to ASB failure. For other cases, friction effect is more important due to large surface contact (hole enlargement). Using adaptive mesh the residual velocity is higher when using fixed mesh for blunt, hemispherical and conical nose shape. In fact using an adaptive mesh option, the 


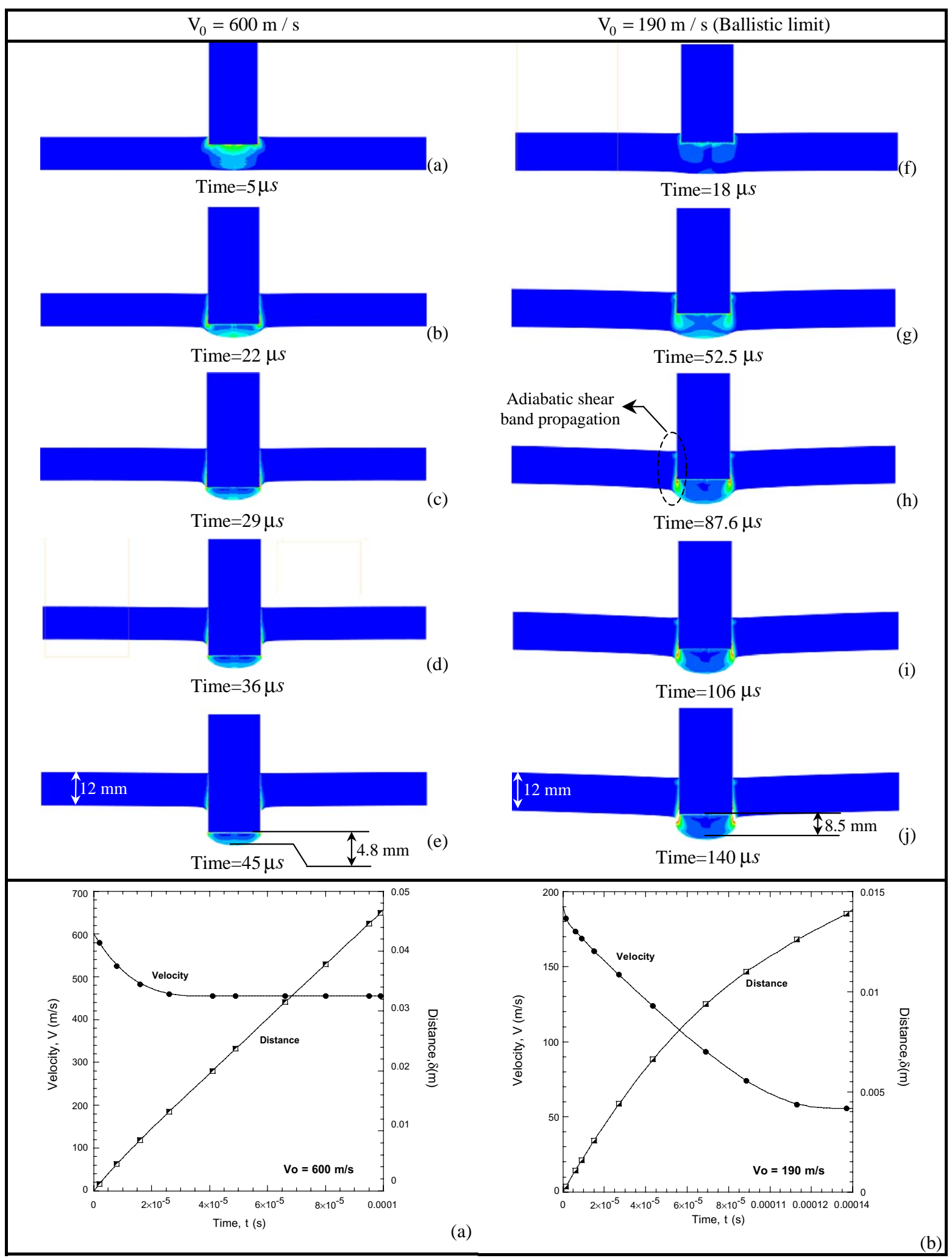

Fig. 10. Numerical simulation of plate perforation process for blunt nose shape. Left: (a) $V_{0}=600 \mathrm{~m} / \mathrm{s}$; Right: (b) $V_{0}=190 \mathrm{~m} / \mathrm{s}$. 


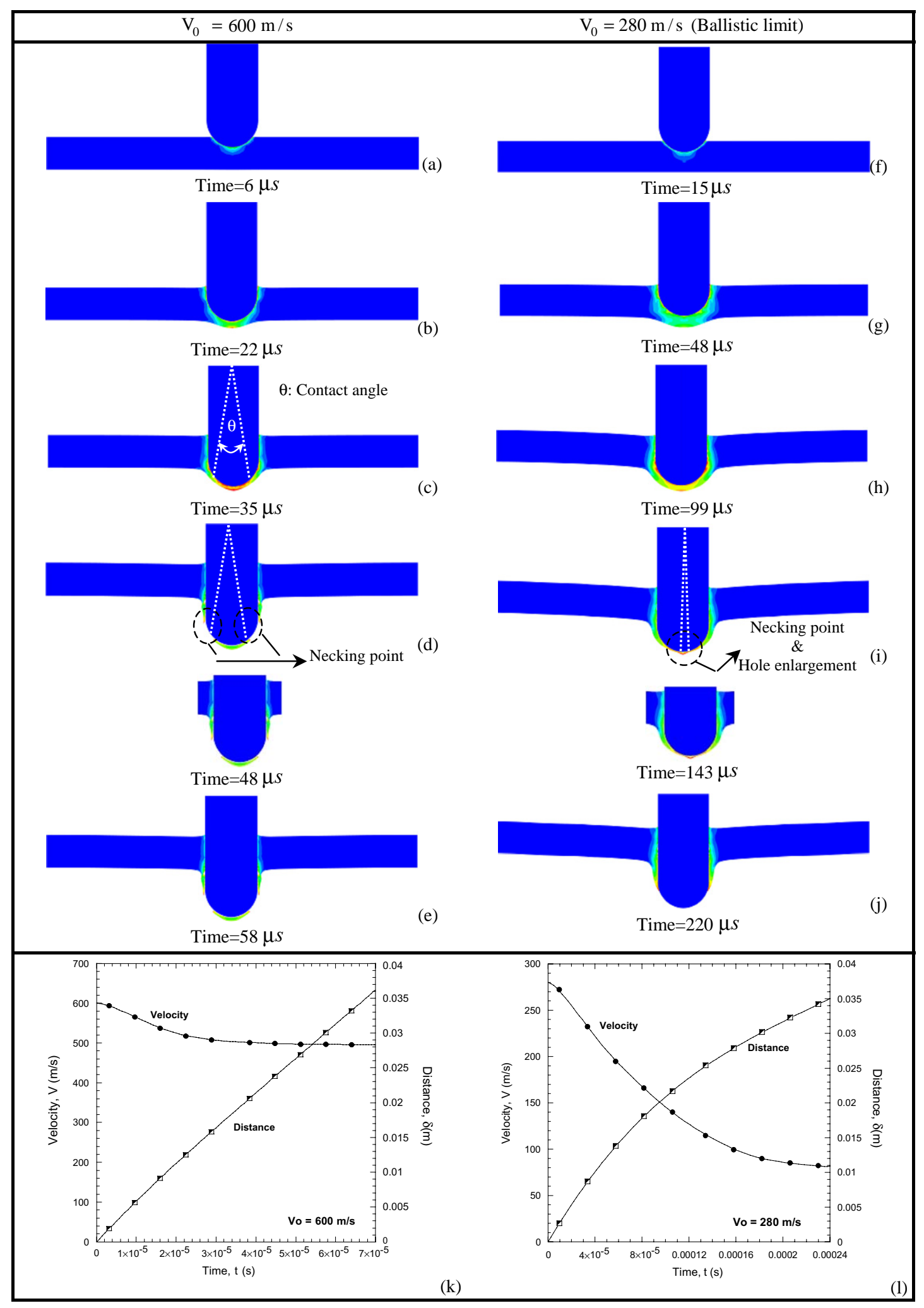

Fig. 11. Numerical simulation of plate perforation process for hemispherical nose shape. Left: $V_{0}=600 \mathrm{~m} / \mathrm{s}$. Right: $V_{0}=280 \mathrm{~m} / \mathrm{s}$. 


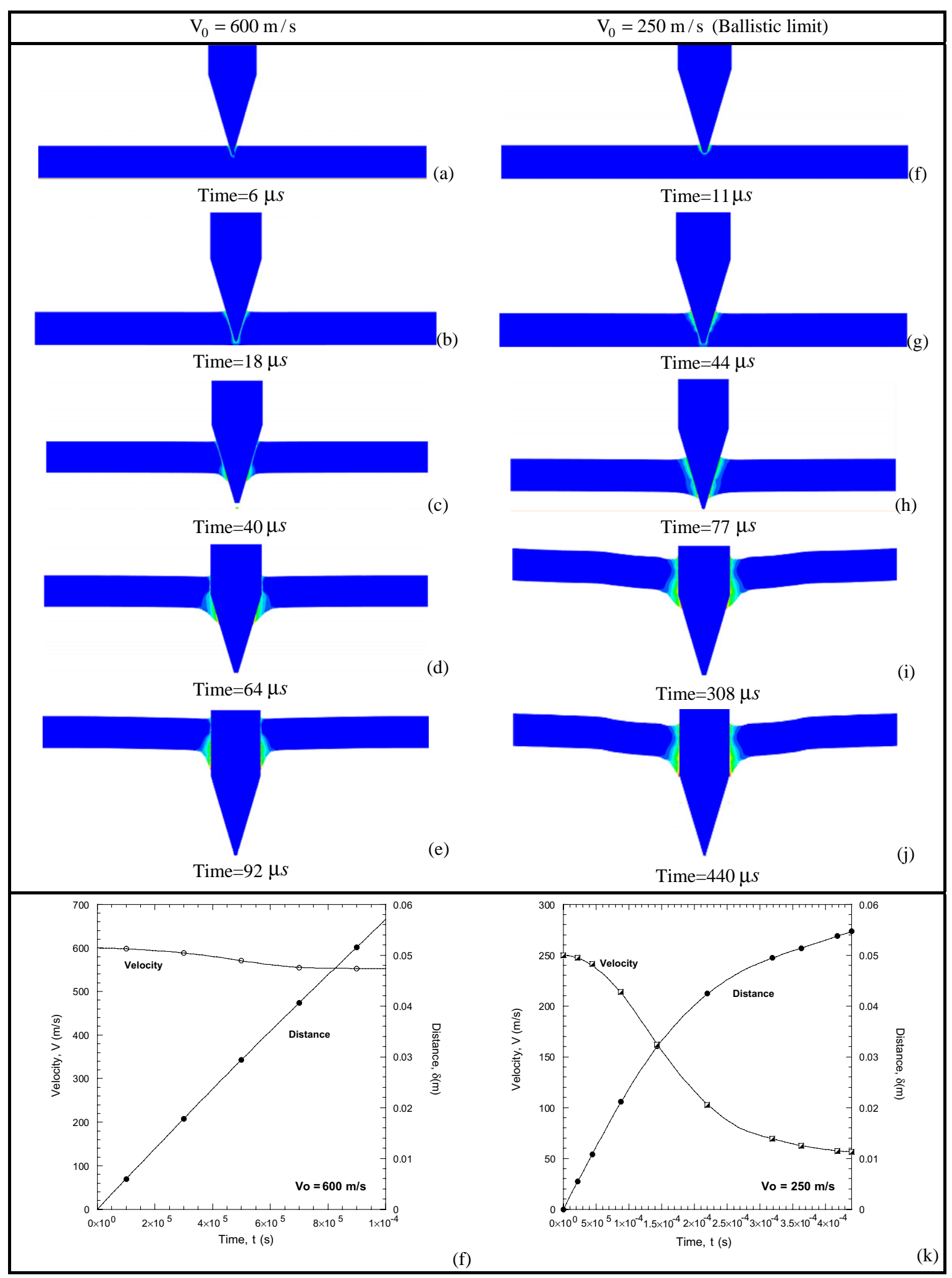

Fig. 12. Numerical simulation of plate perforation process for conical nose shape. Left: (a) $V_{0}=600 \mathrm{~m} / \mathrm{s}$. Right: (b) $V_{0}=250 \mathrm{~m} / \mathrm{s}$. 


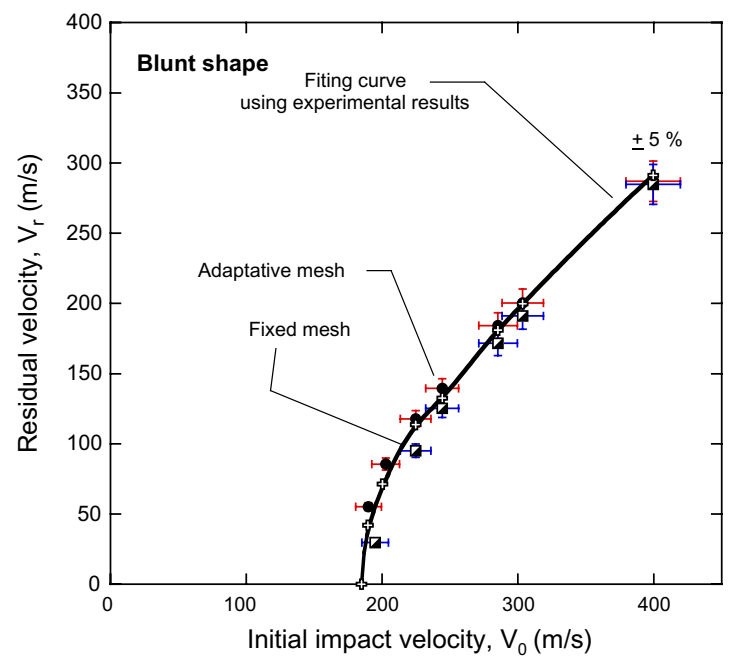

Fig. 13. Numerical estimation of the residual velocity and comparison with experimental results, blunt projectile (B).

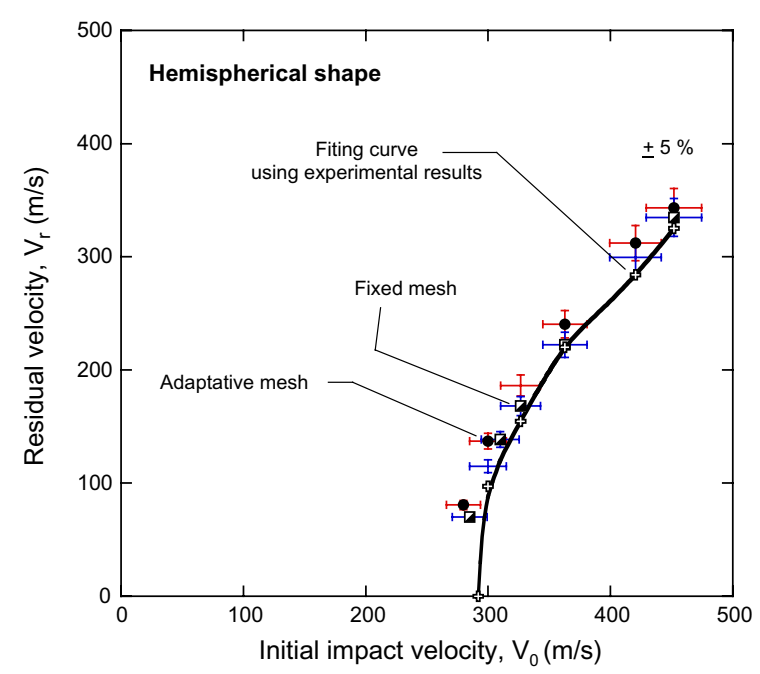

Fig. 14. Numerical estimation of the residual velocity and comparison with experimental results, hemispherical projectile (H).

algorithm allows having a more or less constant length mesh and in this case, the local strain rate is lower in comparison with a fixed mesh. Moreover, using a fixed mesh, the plastic deformation increases quicker in comparison with an adaptive mesh where the length is more or less always the same during calculation. For an adaptive mesh the failure is faster inducing a resistance decrease and the residual velocity is higher.

The constants of Eq. (6), have been estimated using numerical results, Tables A1 A6 (see Appendix). As observed during experiments, the ballistic velocity is lower for blunt nose projectile and close to $V_{b}^{\text {blunt }} \approx 180 \mathrm{~m} / \mathrm{s}$ (Fig. 16). The failure mode appears by adiabatic shear band propagation (Fig. 10) inducing a plug ejection with the same diameter of the projectile. Concerning hemispherical and conical nose shape, the ballistic velocity is of the same order varying from $250 \leqslant V_{\mathrm{b}}^{\mathrm{C}, \mathrm{H}} \leqslant 270 \mathrm{~m} / \mathrm{s}$ (Figs. 17 and 18) in agreement also with experiments [1]. It is also observed that for conical configuration, the residual velocity $V_{\mathrm{r}}$ tends to the initial impact velocity $V_{0}$ notably for very high impact velocity $V_{0}>500 \mathrm{~m} / \mathrm{s}$. Several formulations have been proposed to define the ballistic limit as a function of the initial impact velocity [6]. The most frequently used is the relation reported in [31] allowing to define the residual velocity $V_{\mathrm{r}}$ with the specific parameters of the plug and the projectile: 


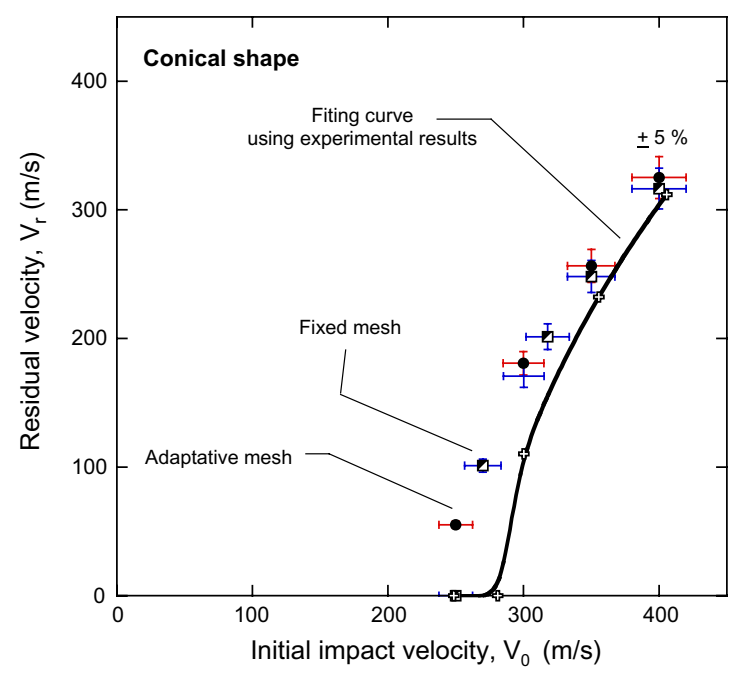

Fig. 15. Numerical estimation of the residual velocity and comparison with experimental results, conical projectile (C).

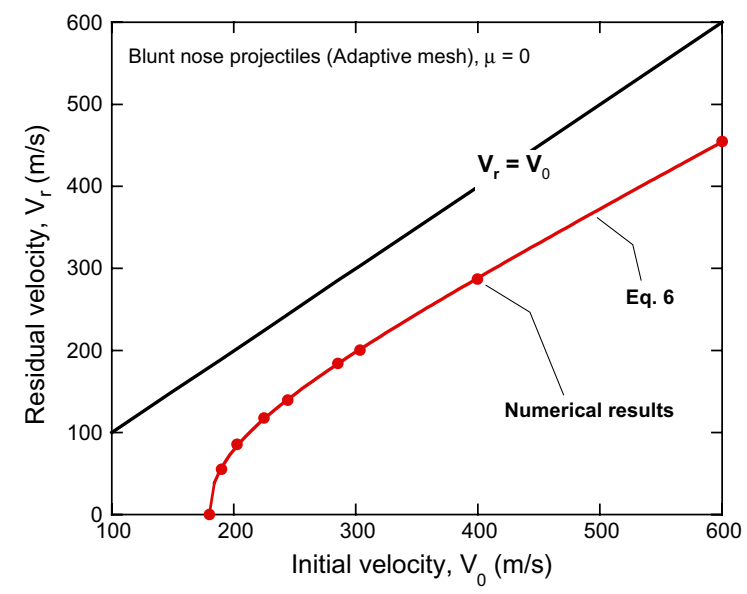

Fig. 16. Definition of the residual velocity using Eq. (6), comparison with numerical results, blunt projectile (B).

$$
\left\{\begin{array}{l}
V_{\mathrm{r}}=\lambda\left(V_{\mathrm{o}}^{K}-V_{\mathrm{bl}}^{K}\right)^{1 / K} \\
\lambda=\frac{m_{\mathrm{p}}}{m_{\mathrm{pl}}+m_{\mathrm{p}}}
\end{array} \quad \text { with } K \approx 2\right.
$$

where $m_{\mathrm{pl}}$ is the mass of the plug, $m_{\mathrm{p}}$ is the mass of the projectile, $V_{\mathrm{o}}$ is the initial velocity of the projectile, $V_{\mathrm{bl}}$ is the ballistic velocity and $K$ is a fitting constant.

Using numerical results a variation of the constant $\lambda$ is observed, Eq. (6), with the projectile geometry. The coefficient is equal to $\lambda_{\text {conical }} \rightarrow 1$ for conical nose shape and to $\lambda_{\text {blunt }} \rightarrow 0.779$ for blunt nose shape. These values are in perfect agreement with experimental results. For blunt projectiles, the failure mode appears by adiabatic shear band propagation creating a plug ejection where $m_{\mathrm{pl}}>0$ and in this case $\lambda<1$, Eq. (6). For conical nose shape, the perforation is due to hole enlargement without plug ejection thus in this last case $m_{\mathrm{pl}} \rightarrow 0$ inducing $\lambda \approx 1$. For hemispherical nose shape $\mathrm{H}$, the configuration is between the configuration $\mathrm{B}$ and $\mathrm{C}$ since the perforation appears also by a small plug ejection and a hole enlargement, thus the value of $\lambda_{\text {hemispherical }}$ is between $0.779<\lambda_{\text {hemispherical }}<1$ (Table 3 ).

The second parameter interesting during this kind of loading is the fracture time $t_{\mathrm{f}}$ corresponding to a complete perforation of the plate. During numerical simulation the fracture time $t_{\mathrm{f}}$ is defined when the force 


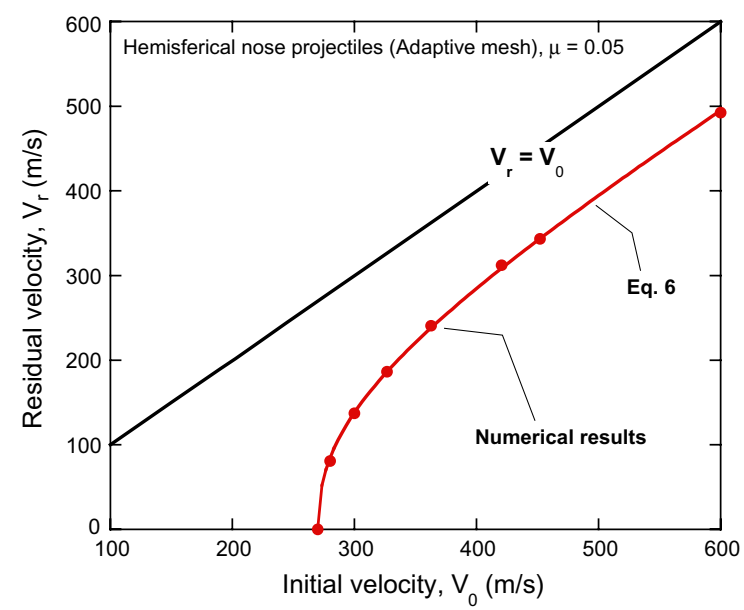

Fig. 17. Definition of the residual velocity using Eq. (6), comparison with numerical results, hemispherical projectile (H).

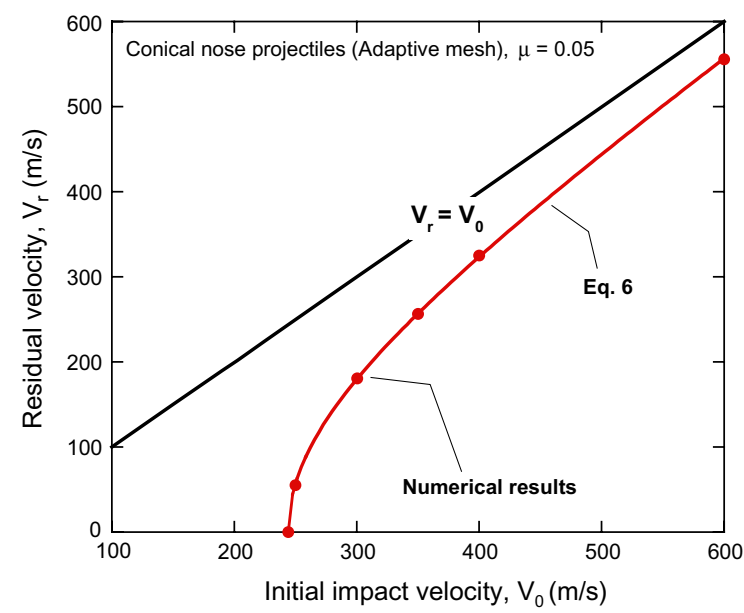

Fig. 18. Definition of the residual velocity using Eq. (6), comparison with numerical results, conical projectile (C).

Table 3

Definition of ballistic limit constants using Eq. (6) for fixed and adaptive mesh

\begin{tabular}{llr}
\hline$\lambda$ (fixed mesh) & $V_{\mathrm{bl}}($ fixed mesh) $(\mathrm{m} / \mathrm{s})$ & $K(\mathrm{fixed} \mathrm{mesh})$ \\
\hline $\begin{array}{l}\text { Blunt projectile (B), Eq. (6) } \\
\quad 0.779(0.813)\end{array}$ & $180(189)$ & $2.267(1.912)$ \\
$\begin{array}{l}\text { Hemispherical projectile (H), Eq. (6) } \\
\quad 0.887(0.902)\end{array}$ & $270(276)$ & $2.323(2.157)$ \\
$\begin{array}{l}\text { Conical projectile (C), Eq. (6) } \\
\quad 1(1)\end{array}$ & $244(250)$ & $2.07(2.03)$ \\
\hline
\end{tabular}

induced to the projectile is equal to $F\left(t_{\mathrm{f}}\right) \quad 0$. Thus, it is observed a good tendency between experimental and numerical results (Figs. 19 and 20). Some differences appear at low impact velocity for blunt and hemispherical configuration. The reason may be linked to the material defects which are very important for low loading as during quasi-static loading. In dynamic loading, due to the rapidity of the process, the defect seems to be less important and numerical results (homogeneous microstructure) are in agreement with experiments. Fig. 21 


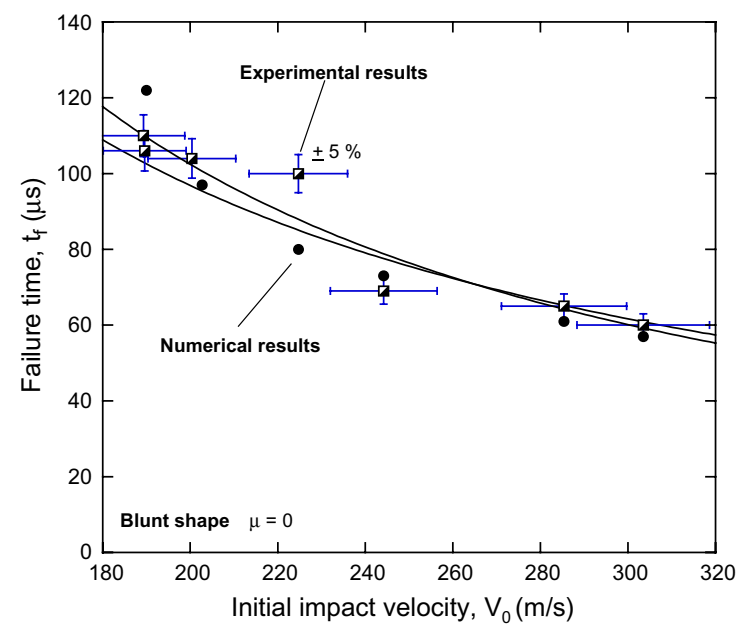

Fig. 19. Numerical estimation of the fracture time and comparison with experimental results, blunt projectile (B).

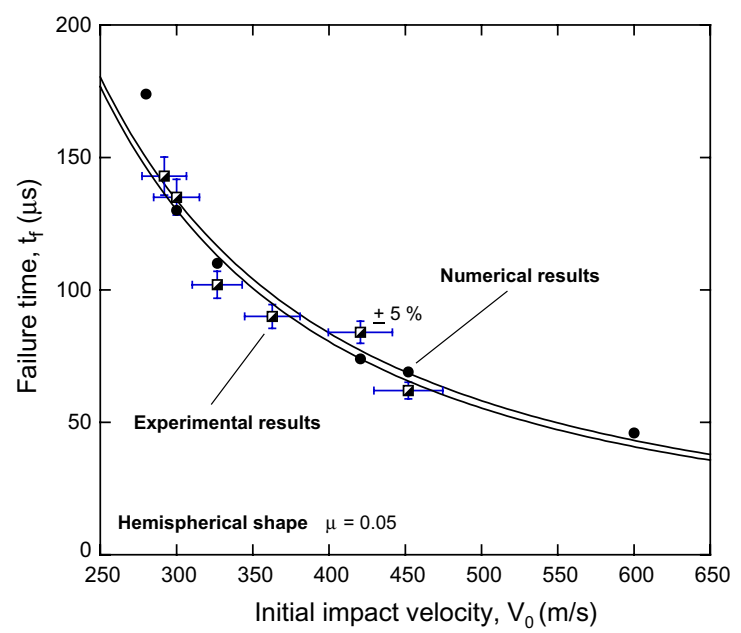

Fig. 20. Numerical estimation of the fracture time and comparison with experimental results, hemispherical projectile (H).

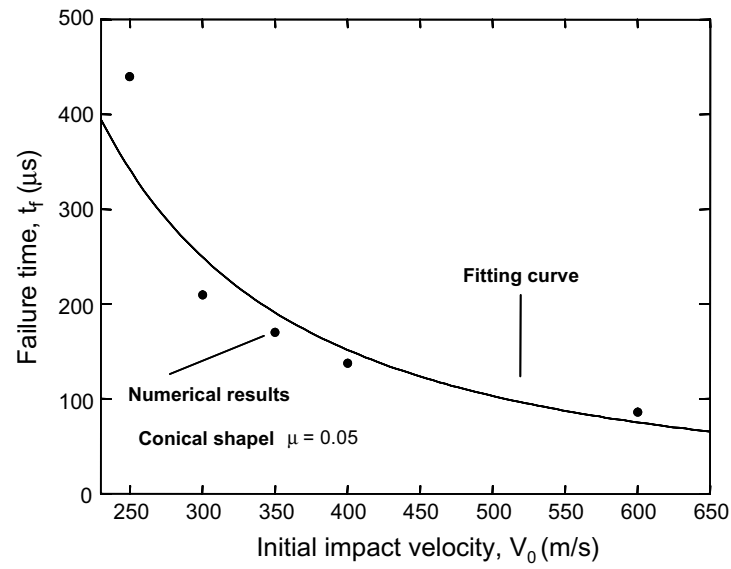

Fig. 21. Numerical estimation of the fracture time and fitting curve, conical projectile (C). 
shows the numerical results for conical shape. In this case, due to the absence of experimental data only numerical results are reported.

Concerning kinetic energy of the projectile converted into work $W$, Eq. (7), evolution with impact velocity is reported (Fig. 22). This tendency is in agreement with experimental results published in the literature $[1,4,3234]$. For hemispherical and blunt noses, $W$ increases with initial velocity because the slope of the residual velocity (Figs. 16 and 17) is equal or minor than 1, while for conical nose, $W$ decreases due to the slope of residual velocity increases with initial impact velocity $V_{0}$ (Fig. 18).

$$
W=\frac{1}{2} m_{\mathrm{p}}\left(V_{0}^{2}-V_{\mathrm{r}}^{2}\right)
$$

Concerning plastic work $W_{\mathrm{p}}$ obtained, this quantity decreases with initial impact velocity for the three nose shapes considered (Fig. 23). The reason is that increment of impact velocity reduces plastic zone and produces damage localisation. For blunt projectiles, the plastic zone is smaller than the others cases since ASB limits plastic energy (thin plastic deformation band). However, for conical projectiles the plastic work is higher due to the predominance of strain rate sensitivity effect and also because the permanent radial compressive state and hole enlargement increase the volume deformed. Finally, for hemispherical projectiles a change of the behaviour is observed: low initial impact velocity generates necking on the top of the contact zone projectile-plate on contrary at high initial velocity, trapping of plastic deformation appears locally inducing a reduction of the volume deformed (Fig. 11).

An estimation of the temperature during the process of plastic deformation has been performed for a velocity corresponding to the ballistic limit and a velocity of $V_{0} \quad 600 \mathrm{~m} / \mathrm{s}$ (Fig. 24). An increase of the temperature is observed during perforation process. However, for high impact velocity the temperature seems to be lower. The reason is certainly due to bending effect which induces an increase of plastic work. For high impact velocity the failure appears quickly without bending effect and in this case the plastic work is lower. Generally, the tendency of the temperature is an increase with an average value corresponding to complete failure equal to $\Delta \bar{T}=500 \mathrm{~K}$.

Thus it is observed using these numerical simulations that the behaviour of the material must be well defined since it depends strongly on the strain rate and temperature sensitivity amplified by large deformation. During this kind of application the strain level observed is close or higher to 1 .

Concerning the influence of frictional effect, numerical results for blunt projectiles are very similar for different values of $\mu$ considered (Tables A1 and A2; see Appendix). Moreover, different values of $\mu$ in conical and hemispherical projectiles induce sensitive changes for residual velocity (Tables A3 A6).

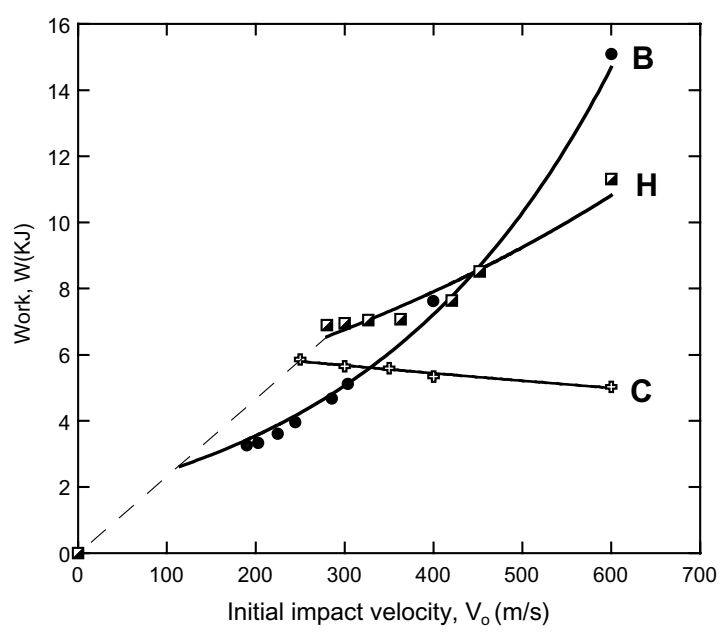

Fig. 22. Numerical initial kinetic energy converted to work $W$ : (a) blunt projectile (B); (b) hemispherical projectile (H); (c) conical projectile (C). 


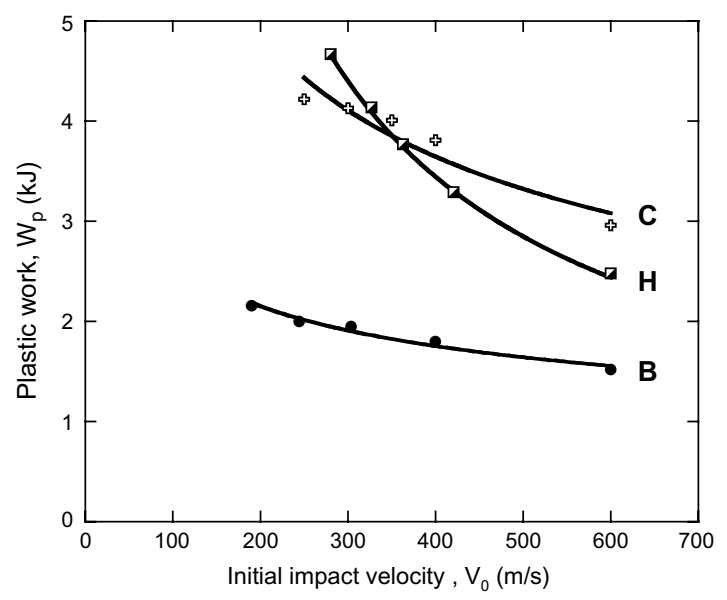

Fig. 23. Plastic work $W_{\mathrm{p}}$ : (a) blunt projectile (B); (b) hemispherical projectile (H); (c) conical projectile (C).

Initial thickness, $\mathrm{h}=12 \mathrm{~mm}$

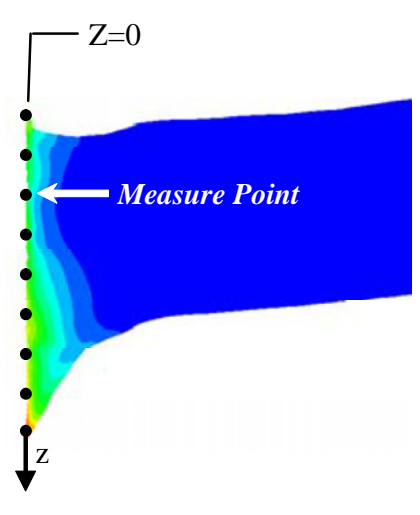

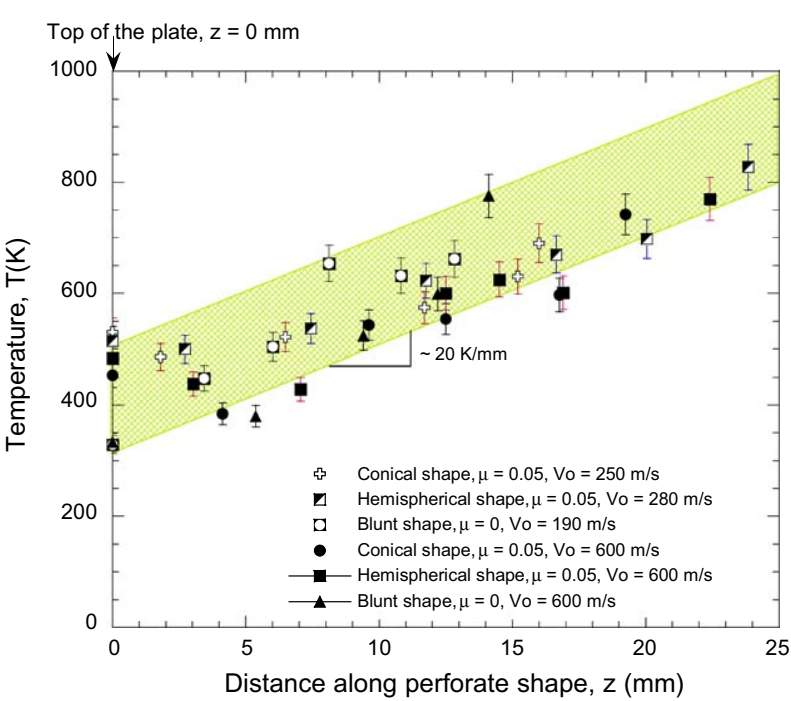

Fig. 24. (a) Definition of $z$ coordinate along the perforated shape. (b) Temperature increase during perforation process for all nose shape configuration.

\section{Conclusions}

In conclusion it is possible to predict accurately with numerical simulations the impact failure mode as observed during experiments depending on the nose shape. With blunt nose shape the failure mode appears by adiabatic shear band propagation inducing plug ejection as final stage. Conical projectiles produce permanent radial compressive state and hole enlargement. Hemispherical projectile combines previous failure modes depending on impact velocity. It is possible to predict the ballistic limit and the fracture time in agreement with experimental values published in the literature $[4,7,32]$ without strong effect between adaptive or fixed mesh (see Appendix). The difference between these two approaches is linked to the convergence during numerical simulation. In some cases using fixed mesh, the calculation is stopped due to element distortion. Using ALE approach, this problem is reduced maintaining the high quality of the mesh through the process. It is also observed that kinetic energy converted to plastic work is related to the failure mode linked to each projectile nose shape and strain rate sensitivity effect of the material used to define the plate behaviour. 


\section{Acknowledgements}

The authors are indebted to the Comunidad Autónoma de Madrid (Project CCG06-UC3M/DPI-0796) for the financial support of this work.

\section{Appendix}

See Tables A1 A6.

Table A1

Blunt nose shape for $\mu=0$

\begin{tabular}{|c|c|c|c|c|c|c|}
\hline$V_{\mathrm{i}}(\mathrm{m} / \mathrm{s})$ & $V_{\mathrm{r}}(\mathrm{m} / \mathrm{s})$ & $t_{\mathrm{f}}(\mu \mathrm{s})$ & $K_{\mathrm{ip}}(\mathrm{kJ})$ & $K_{\mathrm{fp}}(\mathrm{kJ})$ & $W(\mathrm{~kJ})$ & Mesh used \\
\hline \multirow[t]{2}{*}{600.0} & 454.8 & 31 & 35.46 & 20.37 & 15.09 & Adaptive \\
\hline & 455.5 & 33 & 35.46 & 20.44 & 15.02 & Fixed \\
\hline \multirow[t]{2}{*}{399.6} & 287.0 & 44 & 15.73 & 8.11 & 7.62 & Adaptive \\
\hline & 284.8 & 47 & 15.73 & 7.99 & 7.74 & Fixed \\
\hline \multirow[t]{2}{*}{303.5} & 200.4 & 57 & 9.07 & 3.96 & 5.12 & Adaptive \\
\hline & 191.1 & 62 & 9.07 & 3.60 & 5.48 & Fixed \\
\hline \multirow[t]{2}{*}{285.4} & 184.2 & 61 & 8.02 & 3.34 & 4.68 & Adaptive \\
\hline & 171.5 & 66 & 8.02 & 2.90 & 5.13 & Fixed \\
\hline \multirow[t]{2}{*}{244.2} & 139.5 & 73 & 5.87 & 1.92 & 3.96 & Adaptive \\
\hline & 125.2 & 77 & 5.87 & 1.54 & 4.33 & Fixed \\
\hline \multirow[t]{2}{*}{224.7} & 117.8 & 80 & 4.97 & 1.37 & 3.61 & Adaptive \\
\hline & 95.1 & 90 & 4.97 & 0.89 & 4.08 & Fixed \\
\hline \multirow[t]{2}{*}{202.7} & 85.6 & 97 & 4.05 & 0.72 & 3.33 & Adaptive \\
\hline & $\mathrm{nc}$ & $\mathrm{nc}$ & $\mathrm{nc}$ & $\mathrm{nc}$ & $\mathrm{nc}$ & Fixed \\
\hline \multirow[t]{2}{*}{195.0} & $\mathrm{nc}$ & $\mathrm{nc}$ & $\mathrm{nc}$ & $\mathrm{nc}$ & $\mathrm{nc}$ & Adaptive \\
\hline & 29.6 & 157 & 3.75 & 0.09 & 3.66 & Fixed \\
\hline \multirow[t]{2}{*}{190.0} & 55.2 & 122 & 3.56 & 0.30 & 3.26 & Adaptive \\
\hline & $\mathrm{nc}$ & $\mathrm{nc}$ & $\mathrm{nc}$ & $\mathrm{nc}$ & $\mathrm{nc}$ & Fixed \\
\hline
\end{tabular}

$\mathrm{nc}=$ not calculated.

Table A2

Blunt nose shape for $\mu=0.05$

\begin{tabular}{|c|c|c|c|c|c|c|}
\hline$V_{\mathrm{i}}(\mathrm{m} / \mathrm{s})$ & $V_{\mathrm{r}}(\mathrm{m} / \mathrm{s})$ & $t_{\mathrm{f}}(\mu \mathrm{s})$ & $K_{\mathrm{ip}}(\mathrm{kJ})$ & $K_{\mathrm{fp}}(\mathrm{kJ})$ & $W(\mathrm{~kJ})$ & Mesh used \\
\hline 600.0 & $\begin{array}{l}454.9 \\
455.5\end{array}$ & $\begin{array}{l}31 \\
32\end{array}$ & $\begin{array}{l}35.46 \\
35.46\end{array}$ & $\begin{array}{l}20.38 \\
20.44\end{array}$ & $\begin{array}{l}15.08 \\
15.02\end{array}$ & $\begin{array}{l}\text { Adaptive } \\
\text { Fixed }\end{array}$ \\
\hline 399.6 & $\begin{array}{l}286.2 \\
283.8\end{array}$ & $\begin{array}{l}45 \\
47\end{array}$ & $\begin{array}{l}15.73 \\
15.73\end{array}$ & $\begin{array}{l}8.07 \\
7.93\end{array}$ & $\begin{array}{l}7.66 \\
7.80\end{array}$ & $\begin{array}{l}\text { Adaptive } \\
\text { Fixed }\end{array}$ \\
\hline 303.5 & $\begin{array}{l}200.1 \\
187.2\end{array}$ & $\begin{array}{l}57 \\
64\end{array}$ & $\begin{array}{l}9.07 \\
9.07\end{array}$ & $\begin{array}{l}3.94 \\
3.45\end{array}$ & $\begin{array}{l}5.13 \\
5.62\end{array}$ & $\begin{array}{l}\text { Adaptive } \\
\text { Fixed }\end{array}$ \\
\hline 285.4 & $\begin{array}{l}180.2 \\
\text { nc }\end{array}$ & $\begin{array}{l}61 \\
\mathrm{nc}\end{array}$ & $\begin{array}{l}8.02 \\
\mathrm{nc}\end{array}$ & $\begin{array}{l}3.20 \\
\mathrm{nc}\end{array}$ & $\begin{array}{l}4.82 \\
\mathrm{nc}\end{array}$ & $\begin{array}{l}\text { Adaptive } \\
\text { Fixed }\end{array}$ \\
\hline 244.2 & $\begin{array}{l}\mathrm{nc} \\
124.8\end{array}$ & $\begin{array}{l}\mathrm{nc} \\
73\end{array}$ & $\begin{array}{l}\mathrm{nc} \\
5.87\end{array}$ & $\begin{array}{l}\mathrm{nc} \\
1.53\end{array}$ & $\begin{array}{l}\mathrm{nc} \\
4.34\end{array}$ & $\begin{array}{l}\text { Adaptive } \\
\text { Fixed }\end{array}$ \\
\hline 224.7 & $\begin{array}{l}116.3 \\
\mathrm{nc}\end{array}$ & $\begin{array}{l}79 \\
\mathrm{nc}\end{array}$ & $\begin{array}{l}4.97 \\
\mathrm{nc}\end{array}$ & $\begin{array}{l}1.33 \\
\mathrm{nc}\end{array}$ & $\begin{array}{l}3.64 \\
\mathrm{nc}\end{array}$ & $\begin{array}{l}\text { Adaptive } \\
\text { Fixed }\end{array}$ \\
\hline 190.0 & $\begin{array}{l}25.2 \\
0\end{array}$ & 160 & $\begin{array}{l}3.56 \\
3.56\end{array}$ & $\begin{array}{l}0.06 \\
0.00\end{array}$ & $\begin{array}{l}3.49 \\
3.56\end{array}$ & $\begin{array}{l}\text { Adaptive } \\
\text { Fixed }\end{array}$ \\
\hline
\end{tabular}

$\mathrm{nc}=$ not calculated. 
Table A3

Hemispherical t nose shape for $\mu=0$

\begin{tabular}{|c|c|c|c|c|c|c|}
\hline$V_{\mathrm{i}}(\mathrm{m} / \mathrm{s})$ & $V_{\mathrm{r}}(\mathrm{m} / \mathrm{s})$ & $t_{\mathrm{f}}(\mu \mathrm{s})$ & $K_{\text {ip }}(\mathrm{kJ})$ & $K_{\mathrm{fp}}(\mathrm{kJ})$ & $W(\mathrm{~kJ})$ & Mesh used \\
\hline 600.0 & $\begin{array}{l}503.1 \\
\mathrm{nc}\end{array}$ & $\begin{array}{l}48 \\
\mathrm{nc}\end{array}$ & $\begin{array}{l}35.46 \\
\mathrm{nc}\end{array}$ & $\begin{array}{l}24.93 \\
\mathrm{nc}\end{array}$ & $\begin{array}{l}10.53 \\
\mathrm{nc}\end{array}$ & $\begin{array}{l}\text { Adaptive } \\
\text { Fixed }\end{array}$ \\
\hline 452.0 & $\begin{array}{l}356.8 \\
350.1\end{array}$ & $\begin{array}{l}69 \\
70\end{array}$ & $\begin{array}{l}20.12 \\
20.12\end{array}$ & $\begin{array}{l}12.54 \\
12.07\end{array}$ & $\begin{array}{l}7.58 \\
8.05\end{array}$ & $\begin{array}{l}\text { Adaptive } \\
\text { Fixed }\end{array}$ \\
\hline 420.6 & $\begin{array}{l}323.9 \\
\mathrm{nc}\end{array}$ & $\begin{array}{l}76 \\
\mathrm{nc}\end{array}$ & $\begin{array}{l}17.43 \\
\mathrm{nc}\end{array}$ & $\begin{array}{l}10.33 \\
\mathrm{nc}\end{array}$ & $\begin{array}{l}7.09 \\
\mathrm{nc}\end{array}$ & $\begin{array}{l}\text { Adaptive } \\
\text { Fixed }\end{array}$ \\
\hline 362.9 & $\begin{array}{l}253.5 \\
245.2\end{array}$ & $\begin{array}{l}80 \\
96\end{array}$ & $\begin{array}{l}12.97 \\
12.97\end{array}$ & $\begin{array}{l}6.33 \\
5.92\end{array}$ & $\begin{array}{l}6.64 \\
7.05\end{array}$ & $\begin{array}{l}\text { Adaptive } \\
\text { Fixed }\end{array}$ \\
\hline 326.7 & $\begin{array}{l}207.2 \\
\mathrm{nc}\end{array}$ & $\begin{array}{l}100 \\
\mathrm{nc}\end{array}$ & $\begin{array}{l}10.51 \\
\mathrm{nc}\end{array}$ & $\begin{array}{l}4.23 \\
\mathrm{nc}\end{array}$ & $\begin{array}{l}6.28 \\
\mathrm{nc}\end{array}$ & $\begin{array}{l}\text { Adaptive } \\
\text { Fixed }\end{array}$ \\
\hline 310.0 & $\begin{array}{l}182.7 \\
\mathrm{nc}\end{array}$ & $\begin{array}{l}117 \\
\mathrm{nc}\end{array}$ & $\begin{array}{l}9.47 \\
\mathrm{nc}\end{array}$ & $\begin{array}{l}3.29 \\
\mathrm{nc}\end{array}$ & $\begin{array}{l}6.18 \\
\mathrm{nc}\end{array}$ & $\begin{array}{l}\text { Adaptive } \\
\text { Fixed }\end{array}$ \\
\hline 300.0 & $\begin{array}{l}\mathrm{nc} \\
146.4\end{array}$ & $\begin{array}{l}\mathrm{nc} \\
133\end{array}$ & $\begin{array}{l}\mathrm{nc} \\
8.87\end{array}$ & $\begin{array}{l}\mathrm{nc} \\
2.11\end{array}$ & $\begin{array}{l}\mathrm{nc} \\
6.75\end{array}$ & $\begin{array}{l}\text { Adaptive } \\
\text { Fixed }\end{array}$ \\
\hline 280.0 & $\begin{array}{l}121.1 \\
98.1\end{array}$ & $\begin{array}{l}150 \\
162\end{array}$ & $\begin{array}{l}7.72 \\
7.72\end{array}$ & $\begin{array}{l}1.44 \\
0.95\end{array}$ & $\begin{array}{l}6.28 \\
6.77\end{array}$ & $\begin{array}{l}\text { Adaptive } \\
\text { Fixed }\end{array}$ \\
\hline 260.0 & $\begin{array}{l}\mathrm{nc} \\
0\end{array}$ & $\mathrm{nc}$ & $\begin{array}{l}\mathrm{nc} \\
6.66\end{array}$ & $\begin{array}{l}\text { nc } \\
0.00\end{array}$ & $\begin{array}{l}\mathrm{nc} \\
6.66\end{array}$ & $\begin{array}{l}\text { Adaptive } \\
\text { Fixed }\end{array}$ \\
\hline
\end{tabular}

$\mathrm{nc}=$ not calculated.

Table A4

Hemispherical $\mathrm{t}$ nose shape for $\mu=0.05$

\begin{tabular}{|c|c|c|c|c|c|c|}
\hline$V_{\mathrm{i}}(\mathrm{m} / \mathrm{s})$ & $V_{\mathrm{r}}(\mathrm{m} / \mathrm{s})$ & $t_{\mathrm{f}}(\mu \mathrm{s})$ & $K_{\mathrm{ip}}(\mathrm{kJ})$ & $K_{\mathrm{fp}}(\mathrm{kJ})$ & $W(\mathrm{~kJ})$ & Mesh used \\
\hline 600.0 & $\begin{array}{l}492.2 \\
490.4\end{array}$ & $\begin{array}{l}46 \\
49\end{array}$ & $\begin{array}{l}35.46 \\
35.46\end{array}$ & $\begin{array}{l}23.86 \\
23.69\end{array}$ & $\begin{array}{l}11.31 \\
11.77\end{array}$ & $\begin{array}{l}\text { Adaptive } \\
\text { Fixed }\end{array}$ \\
\hline 452.0 & $\begin{array}{l}343.3 \\
334.8\end{array}$ & $\begin{array}{l}69 \\
74\end{array}$ & $\begin{array}{l}20.12 \\
20.12\end{array}$ & $\begin{array}{l}11.61 \\
11.04\end{array}$ & $\begin{array}{l}8.52 \\
9.08\end{array}$ & $\begin{array}{l}\text { Adaptive } \\
\text { Fixed }\end{array}$ \\
\hline 420.6 & $\begin{array}{l}312.2 \\
299.6\end{array}$ & $\begin{array}{l}74 \\
76\end{array}$ & $\begin{array}{l}17.43 \\
17.43\end{array}$ & $\begin{array}{l}9.60 \\
8.84\end{array}$ & $\begin{array}{l}7.64 \\
8.58\end{array}$ & $\begin{array}{l}\text { Adaptive } \\
\text { Fixed }\end{array}$ \\
\hline 362.9 & $\begin{array}{l}240.6 \\
222.3\end{array}$ & $\begin{array}{l}90 \\
93\end{array}$ & $\begin{array}{l}12.97 \\
12.97\end{array}$ & $\begin{array}{l}5.75 \\
4.87\end{array}$ & $\begin{array}{l}7.05 \\
8.10\end{array}$ & $\begin{array}{l}\text { Adaptive } \\
\text { Fixed }\end{array}$ \\
\hline 326.7 & $\begin{array}{l}186.3 \\
168.2\end{array}$ & $\begin{array}{l}110 \\
122\end{array}$ & $\begin{array}{l}10.51 \\
10.51\end{array}$ & $\begin{array}{l}3.38 \\
2.79\end{array}$ & $\begin{array}{l}6.95 \\
7.73\end{array}$ & $\begin{array}{l}\text { Adaptive } \\
\text { Fixed }\end{array}$ \\
\hline 310.0 & $\begin{array}{l}\mathrm{nc} \\
138.6\end{array}$ & $\begin{array}{l}\mathrm{nc} \\
131\end{array}$ & $\begin{array}{l}\mathrm{nc} \\
9.47\end{array}$ & $\begin{array}{l}\mathrm{nc} \\
1.89\end{array}$ & $\begin{array}{l}\mathrm{nc} \\
7.57\end{array}$ & $\begin{array}{l}\text { Adaptive } \\
\text { Fixed }\end{array}$ \\
\hline 300.0 & $\begin{array}{l}137.2 \\
115.0\end{array}$ & $\begin{array}{l}130 \\
153\end{array}$ & $\begin{array}{l}8.87 \\
8.87\end{array}$ & $\begin{array}{l}1.96 \\
1.30\end{array}$ & $\begin{array}{l}6.90 \\
7.56\end{array}$ & $\begin{array}{l}\text { Adaptive } \\
\text { Fixed }\end{array}$ \\
\hline 285.0 & $\begin{array}{l}\mathrm{nc} \\
70.2\end{array}$ & $\begin{array}{l}\mathrm{nc} \\
182\end{array}$ & $\begin{array}{l}\mathrm{nc} \\
8.00\end{array}$ & $\begin{array}{l}\mathrm{nc} \\
0.49\end{array}$ & $\begin{array}{l}\mathrm{nc} \\
7.52\end{array}$ & $\begin{array}{l}\text { Adaptive } \\
\text { Fixed }\end{array}$ \\
\hline 280.0 & $\begin{array}{l}80.8 \\
\mathrm{nc}\end{array}$ & $\begin{array}{l}174 \\
\mathrm{nc}\end{array}$ & $\begin{array}{l}7.72 \\
\mathrm{nc}\end{array}$ & $\begin{array}{l}0.64 \\
\mathrm{nc}\end{array}$ & $\begin{array}{l}7.08 \\
\mathrm{nc}\end{array}$ & $\begin{array}{l}\text { Adaptive } \\
\text { Fixed }\end{array}$ \\
\hline
\end{tabular}

$\mathrm{nc}=$ not calculated 
Table A5

Conical nose shape for $\mu=0$

\begin{tabular}{|c|c|c|c|c|c|c|}
\hline$V_{\mathrm{i}}(\mathrm{m} / \mathrm{s})$ & $V_{\mathrm{r}}(\mathrm{m} / \mathrm{s})$ & $t_{\mathrm{f}}(\mu \mathrm{s})$ & $K_{\text {ip }}(\mathrm{kJ})$ & $K_{\mathrm{fp}}(\mathrm{kJ})$ & $W(\mathrm{~kJ})$ & Mesh used \\
\hline & 336.8 & 135 & 15.76 & 11.17 & 4.59 & Adaptive \\
\hline & 332.6 & 140 & 15.76 & 10.90 & 4.86 & Fixed \\
\hline \multirow[t]{2}{*}{350.0} & $\mathrm{nc}$ & $\mathrm{nc}$ & $\mathrm{nc}$ & $\mathrm{nc}$ & $\mathrm{nc}$ & Adaptive \\
\hline & 268.4 & 165 & 12.07 & 7.10 & 4.97 & Fixed \\
\hline \multirow[t]{2}{*}{300.0} & 205.8 & 200 & 8.87 & 4.17 & 4.69 & Adaptive \\
\hline & 196 & 211 & 8.87 & 3.78 & 5.08 & Fixed \\
\hline \multirow[t]{2}{*}{275.0} & 165.9 & 240 & 7.45 & 2.71 & 4.74 & Adaptive \\
\hline & $\mathrm{nc}$ & $\mathrm{nc}$ & $\mathrm{nc}$ & $\mathrm{nc}$ & $\mathrm{nc}$ & Fixed \\
\hline \multirow[t]{2}{*}{250.0} & 113.8 & 320 & 6.16 & 1.28 & 4.88 & Adaptive \\
\hline & 91.94 & 340 & 6.16 & 0.83 & 5.32 & Fixed \\
\hline \multirow[t]{2}{*}{230.0} & $\mathrm{nc}$ & $\mathrm{nc}$ & $\mathrm{nc}$ & $\mathrm{nc}$ & $\mathrm{nc}$ & Adaptive \\
\hline & 0 & & 5.21 & 0.00 & 5.21 & Fixed \\
\hline
\end{tabular}

$\mathrm{nc}=$ not calculated.

Table A6

Conical nose shape for $\mu=0.05$

\begin{tabular}{|c|c|c|c|c|c|c|}
\hline$V_{\mathrm{i}}(\mathrm{m} / \mathrm{s})$ & $V_{\mathrm{r}}(\mathrm{m} / \mathrm{s})$ & $t_{\mathrm{f}}(\mu \mathrm{s})$ & $K_{\text {ip }}(\mathrm{kJ})$ & $K_{\mathrm{fp}}(\mathrm{kJ})$ & $W(\mathrm{~kJ})$ & Mesh used \\
\hline 600.0 & $\begin{array}{l}555.8 \\
552.7\end{array}$ & $\begin{array}{l}86 \\
88\end{array}$ & $\begin{array}{l}35.46 \\
35.46\end{array}$ & $\begin{array}{l}30.43 \\
30.09\end{array}$ & $\begin{array}{l}5.03 \\
5.37\end{array}$ & $\begin{array}{l}\text { Adaptive } \\
\text { Fixed }\end{array}$ \\
\hline 400.0 & $\begin{array}{l}325.2 \\
316.5\end{array}$ & $\begin{array}{l}138 \\
144\end{array}$ & $\begin{array}{l}15.76 \\
15.76\end{array}$ & $\begin{array}{l}10.42 \\
9.87\end{array}$ & $\begin{array}{l}5.34 \\
5.89\end{array}$ & $\begin{array}{l}\text { Adaptive } \\
\text { Fixed }\end{array}$ \\
\hline 350.0 & $\begin{array}{l}256.5 \\
248.2\end{array}$ & $\begin{array}{l}170 \\
176\end{array}$ & $\begin{array}{l}12.07 \\
12.07\end{array}$ & $\begin{array}{l}6.48 \\
6.07\end{array}$ & $\begin{array}{l}5.59 \\
6.00\end{array}$ & $\begin{array}{l}\text { Adaptive } \\
\text { Fixed }\end{array}$ \\
\hline 317.9 & $\begin{array}{l}\mathrm{nc} \\
201.4\end{array}$ & $\begin{array}{l}\mathrm{nc} \\
202\end{array}$ & $\begin{array}{l}\mathrm{nc} \\
9.95\end{array}$ & $\begin{array}{l}\mathrm{nc} \\
4.00\end{array}$ & $\begin{array}{l}\mathrm{nc} \\
5.96\end{array}$ & $\begin{array}{l}\text { Adaptive } \\
\text { Fixed }\end{array}$ \\
\hline 300.3 & $\begin{array}{l}\mathrm{nc} \\
170.7\end{array}$ & $\begin{array}{l}\mathrm{nc} \\
225\end{array}$ & $\begin{array}{l}\text { nc } \\
8.88\end{array}$ & $\begin{array}{l}\text { nc } \\
2.87\end{array}$ & $\begin{array}{l}\mathrm{nc} \\
6.01\end{array}$ & $\begin{array}{l}\text { Adaptive } \\
\text { Fixed }\end{array}$ \\
\hline 300.0 & $\begin{array}{l}180.8 \\
\mathrm{nc}\end{array}$ & $\begin{array}{l}210 \\
\mathrm{nc}\end{array}$ & $\begin{array}{l}8.87 \\
\mathrm{nc}\end{array}$ & $\begin{array}{l}3.22 \\
\mathrm{nc}\end{array}$ & $\begin{array}{l}5.65 \\
\mathrm{nc}\end{array}$ & $\begin{array}{l}\text { Adaptive } \\
\text { Fixed }\end{array}$ \\
\hline 250.0 & $\begin{array}{l}55.2 \\
0\end{array}$ & 440 & $\begin{array}{l}6.16 \\
6.16\end{array}$ & $\begin{array}{l}0.30 \\
0.00\end{array}$ & $\begin{array}{l}5.86 \\
6.16\end{array}$ & $\begin{array}{l}\text { Adaptive } \\
\text { Fixed }\end{array}$ \\
\hline
\end{tabular}

$\mathrm{nc}=$ not calculated.

\section{References}

[1] Borvik T, Langseth M, Hoperstad OS, Malo KA. Perforation of $12 \mathrm{~mm}$ thick steel plates by $20 \mathrm{~mm}$ diameter projectiles with flat, hemispherical and conical noses Part I: experimental study. Int J Impact Engng 2002;27:19 35.

[2] Gupta NK, Iqbal MA, Sekhon GS. Experimental and numerical studies on the behaviour of thin aluminium plates subjected to impact by blunt and hemispherical nosed projectiles. Int J Impact Engng 2006;32:1921 44.

[3] Corran RSJ, Shadbolt PJ, Ruiz C. Impact loading of plates an experimental investigation. Int J Impact Engng 1983;1:3 22.

[4] Borvik T, Langseth M, Hoperstad OS, Malo KA. Ballistic penetration of steel plates. Int J Impact Engng 1999;22:855 86.

[5] Chen XW, Li QM, Fan SC. Initiation of adiabatic shear failure in a clamped circular plate struck by a blunt projectile. Int J Impact Engng 2005;31:877 93.

[6] Borvik T, Hopperstad OS, Langseth M, Malo KA. Effect of target thickness in blunt projectile penetration of Weldox 460 E steel plates. Int J Impact Engng 2003;28:413 64

[7] Borvik T, Langseth M, Hoperstad OS, Malo KA. Perforation of $12 \mathrm{~mm}$ thick steel plates by $20 \mathrm{~mm}$ diameter projectiles with flat, hemispherical and conical noses Part II: Numerical study. Int J Impact Engng 2002;27:37 64. 
[8] Hibbitt HD, Karlsson BI, Sorensen P. Abaqus User's manual, ABAQUS/EXPLICIT 6.5; 2005.

[9] Teng X, Wierzbicki T, Hiermaier S, Rohr I. Numerical prediction of fracture in the Taylor test. Int J Solids Struct 2005;42:2929 48.

[10] Rusinek A, Zaera R, Klepaczko JR, Cheriguene R. Analysis of inertia and scale effects on dynamic neck formation during tension of sheet steel. Acta Mater 2005;53(20):5387 400.

[11] Rusinek A, Zaera R. Finite element simulation of steel ring fragmentation under radial expansion. Int J Impact Engng 2007;34(4): 799822.

[12] Chwalik P. Comportement thermomécanique du TA6V en cisaillement quasi statique et par impact direct, rupture adiabatique et analyse numérique par éléments finis, PhD Thesis, University of Metz; 2005.

[13] Rusinek A. Modélisation thermoviscoplastique d'une nuance de tôle d'acier aux grandes vitesses de déformation. Etude expérimentale et numérique du cisaillement, de la traction et de la perforation, PhD Thesis, University of Metz; 2000.

[14] Borvik T, Hopperstad OS, Dey S, Pizzinato V, Langhset M, Albertini C. Strength and ductility of Weldox 460 E steel at high rates, elevated temperatures and various stress triaxialities. Engng Fract Mech 2005;72:1071 87.

[15] Teng X, Wierzbicki T. Evaluation of six fracture models in high velocity perforation. Engng Fract Mech 2006;73:1653 78.

[16] Borvik T, Hoperstad OS, Berstad T, Langseth M. A computational model of viscoplasticity and ductile damage for impact and penetration. Eur J Mech 2001;20:685 712 .

[17] Steinberg DJ, Cochran SG, Guinan MW. Constitutive model for metals applicable at high strain rates. J Appl Phys 1980;51(3): 1498504

[18] Johnson GR, Cook WH. A constitutive model and data for metals subjected to large strains high strain rates and high temperatures. In: Proceedings of the seventh international symposium on ballistics; 1983.

[19] Zerilli FJ, Armstrong RW. Dislocation mechanics based constitutive relations for materials calculations. J Appl Phys 1987;61: 181625.

[20] Quinney H, Taylor GI. The emission of latent energy due to previous cold working when a metal is heated. Proc R Soc Lond 1937; 163:157 81.

[21] Hancock JW, Mackenzie AC. On the mechanisms of ductile failure in high strength steels subjected to multi axial stress states. J Mech Phys Solids 1976;24:147 69.

[22] Johnson GR, Cook WH. Fracture characteristics of three metals subjected to various strains, strain rates, temperatures and pressures. Engng Fract Mech 1985;21(1):31 48.

[23] Wood WW. Experimental mechanics at velocity extremes very high strain rates. Exp Mech 1965;5:361 71.

[24] Camacho GT, Ortiz M. Adaptive Lagrangian modelling of ballistic penetration of metallic targets. Comput Methods Appl Mech Engng 1997;142:269 301.

[25] Zhang TG. Rupture of thin ductile tubes by oblique impact of flat nosed missiles: analysis. Int J Impact Engng 1998;21(7):541 70.

[26] Zaera R, Sanchez Galvez V. Analytical modelling of normal and oblique ballistic impact on ceramic/metal lightweight armours. Int J Impact Engng 1998;21(3):133 48.

[27] Zukas JA, Scheffler DR. Practical aspects of numerical simulations of dynamic events: effects of meshing. Int J Impact Engng 2000: 92545.

[28] Piekutowski AJ, Forestal MJ, Poormon KL, Warren TL. Penetration of 6061 T6511 aluminium targets by ogive nose steel projectiles with striking velocities between 0.5 and $3.0 \mathrm{~km} / \mathrm{s}$. Int J Impact Engng 1999;23:723 34.

[29] Bonnet Lebouvier AS, Molinari A, Lipinski P. Analysis of the dynamic propagation of adiabatic shear bands. Int J Solids Struct 2002;39(16):4249 69 .

[30] Klósak M, Lodygowski T, Klepaczcko JR. Remarks on estimation of the critical impact velocity in shear. Comput Assist Mech Engng Sci 2001;8:579 93.

[31] Recht RF, Ipson TW. Ballistic perforation dynamics. J Appl Mech 1963;30:384 90.

[32] Dey S, Borvik T, Hopperstad OS, Leinum JR, Langseth M. The effect of target on the penetration of steel plates using three different projectile nose shapes. Int J Impact Engng 2004;30:1005 38.

[33] Zaera R, Arias A, Navarro C. Analytical modelling of metallic circular plates subjected to impulsive loads. Int J Solids Struct 2002;39:659 72.

[34] Arias A. Desarrollo y modelización del comportamiento frente a impacto de materiales compuestos de matriz polimérica y carga cerámica. PhD Thesis, University Carlos III of Madrid; 2002. 